\title{
Emerging therapies in mantle cell lymphoma
}

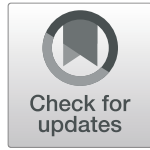

\author{
Walter Hanel and Narendranath Epperla ${ }^{*}$ (D)
}

\begin{abstract}
Mantle cell lymphoma (MCL) is a rare, B cell non-Hodgkin's lymphoma with highly heterogeneous clinical presentation and aggressiveness. First-line treatment consists of intensive chemotherapy with autologous stem cell transplant for the fit, transplant eligible patients, or less intensive chemotherapy for the less fit (and transplantineligible) patients. Patients eventually relapse with a progressive clinical course. Numerous therapeutic approaches have emerged over the last few years which have significantly changed the treatment landscape of MCL. These therapies consist of targeted approaches such as BTK and BCL2 inhibitors that provide durable therapeutic responses. However, the optimum combination and sequencing of these therapies is unclear and is currently investigated in several ongoing studies. Furthermore, cellular therapies such as chimeric antigen receptor (CAR) $T$ cells and bispecific T cell engager (BiTe) antibodies have shown impressive results and will likely shape treatment approaches in relapsed MCL, especially after failure with BTK inhibitors. Herein, we provide a comprehensive review of past and ongoing studies that will likely significantly impact our approach to $\mathrm{MCL}$ treatment in both the frontline (for transplant eligible and ineligible patients) as well as in the relapsed setting. We present the most up to date results from these studies as well as perspectives on future studies in MCL.
\end{abstract}

Keywords: Mantle cell lymphoma, BTK, BCL2, CART, BiTe

\section{Background}

Mantle cell lymphoma (MCL) is a rare, heterogeneous disease comprising around $2.5-6 \%$ of $\mathrm{B}$ cell nonHodgkin lymphoma (NHL) $[1,2]$. The primary genetic alteration in MCL is the chromosomal translocation (11; 14) which leads to CyclinD1 overexpression and uncontrolled cell proliferation. MCL is classified into four morphological variants: leukemic non-nodal, classic, blastoid, and pleomorphic, with the last two considered more aggressive and associated with poorer prognosis [1]. The MCL international prognostic index (MIPI) score stratifies patients based on age, ECOG performance status, LDH, WBC, and Ki-67 positivity into low,

* Correspondence: Narendranath.Epperla@osumc.edu

Division of Hematology, Department of Medicine, The James Cancer Hospital and Solove Research Institute, The Ohio State University, Columbus, $\mathrm{OH}$ 43210, USA intermediate, and prognostic groupings with a 5-year OS of $60 \%$, median OS of 51 months or median OS 29 months, respectively [3]. In addition, TP53 gene mutation at diagnosis is associated with poor response to upfront intensive chemotherapy and poor prognosis [4].

Currently, the approach for the upfront treatment of MCL largely relies on patient-specific factors such as age, overall performance status, and underlying comorbidities. For the young, transplant eligible patient, treatment generally consists of induction chemotherapy followed by consolidation with an autologous hematopoietic stem cell transplant (auto-HCT) followed by maintenance with rituximab for 3 years. For induction chemotherapy, unlike in diffuse large B cell lymphoma (DLBCL), there is no specific chemotherapy regimen that has been firmly established as the standard of care and the specific regimen used is variable based on the institution or physician practice, although it is generally 
accepted that the regimen should contain cytarabine. Common regimens include rituximab/dexamethasone/ cytarabine/cisplatin (R-DHAP), alternating with rituximab/cyclophosphamide/doxorubicin/vincristine/prednisone (R-CHOP) (R-CHOP/R-DHAP), or rituximab/ hyperfractionated cyclophosphamide/vincristine/doxorubicin/dexamethasone alternating with high-dose methotrexate and cytarabine (R-hyperCVAD). For patients unfit for intensive chemotherapy, less toxic chemotherapy treatments are given, such as bendamustine/rituximab (BR) or R-CHOP with or without maintenance rituximab. At disease progression/relapse, targeted agents such as ibrutinib, lenalidomide, bortezomib, or venetoclax are used in succession as monotherapies. Allogeneic HCT (allo-HCT) can provide durable remission in select patients.

The goal of this review is to provide a broad overview of approaches and clinical trials that are currently ongoing in MCL that may lead to novel therapies, some of which may result in significant shifts in the treatment paradigms. Although we will briefly discuss important studies leading to currently approved therapies for MCL, we will reserve much of our focus to ongoing studies in MCL. We will initially begin by reviewing the use of targeted agents including small molecule inhibitors and antibodies in the relapsed/refractory setting and current trials using combinations of these therapies. We will review the exciting new role of cellular therapies in MCL, including chimeric antigen receptor $\mathrm{T}$ (CART) cells and bispecific $\mathrm{T}$ cell engager (BiTe) antibodies. We will then discuss how targeted therapies currently used in the relapsed setting are being moved to upfront therapy to challenge the paradigm of chemoimmunotherapy as sole therapy in this setting. We will finally discuss how riskadapted approaches may soon become incorporated into treatment algorithms for MCL.

\section{Current and future approaches to relapsed/ refractory $M C L$}

\section{Small molecule targeted therapies}

\section{BTK inhibitors}

Bruton's tyrosine kinase (BTK) is an intracellular kinase downstream from the $B$ cell receptor $(B C R)$ required for normal B cell maturation and BCR-mediated proliferation and survival [5]. BTK signals downstream to activate the ERK, PI3K, NF-kappaB, and NFAT signaling pathways via tyrosine phosphorylation of PLC-gamma2. Many cases of MCL have constitutively active BCR signaling and inhibition of BTK by genetic knockdown results in apoptosis, thus confirming BTK as an important therapeutic target in MCL [6]. Aside from direct cytotoxic effects, inhibition of BTK by ibrutinib may have immune-modulatory effects by increasing peripheral CD4 and CD8 T cells [7]. Currently, several BTK inhibitors have been either FDA approved or are in further development for the treatment of MCL (Table 1).

Ibrutinib, a first in class BTK inhibitor, binds covalently to cysteine 481 within the ATP binding domain of BTK resulting in irreversible kinase inhibition. In addition to BTK inhibition, ibrutinib also inhibits interleukin-2 inducible $\mathrm{T}$ cell kinase (ITK), tyrosineprotein kinase (TEC), and the epidermal growth factor receptor kinase (EGFR). In the pivotal phase 2 study of relapsed/refractory MCL patients $(n=111)$, ibrutinib demonstrated an overall response rate (ORR) of $67 \%$ with a complete response (CR) rate of $23 \%$ leading to its FDA approval after at least one prior line of therapy [8]. The median time to response (TTR) in the study was 1.9 months, and duration of response (DOR) was17.5 months. Most common side effects were diarrhea (54\%), fatigue (50\%), nausea (33\%), and dyspnea (32\%). Fifty percent of patients experienced a bleeding event (grade $\geq 3,5 \%$ ), and $6 \%$ experienced atrial fibrillation (grade $\geq$ $3,5 \%)$. The efficacy of ibrutinib in relapsed MCL was further confirmed in phase III MCL3001 trial in which patients were randomized to either ibrutinib or temsirolimus $(n=238$ total) [10]. The median PFS was significantly better for patients who received ibrutinib (14.6 months) compared to those who received temsirolimus (6.2 months) $(p<0.0001)$. A pooled analysis of three separate ibrutinib trials $(n=370)$ shown an ORR of $66 \%$ (CR rate, 20\%), with a median PFS and OS of 12.3 months and 25 months, respectively [18]. When this analysis was restricted to the subgroup of patients receiving ibrutinib as the second line, the survival outcomes were considerably better (median PFS as 28 months and OS was not reached).

Acalabrutinib is a second-generation BTK inhibitor that also binds covalently to cysteine 481 but with low activity towards ITK, TEC, and EGFR [19]. Acalabrutinib demonstrated an ORR of $81 \%$ (CR rate of $43 \%$ ) in a phase II study (ACE-LY-2004, $n=124$ ) of relapsed/refractory MCL leading to its FDA approval [11]. At a median follow-up time of 26 months, the median PFS and OS were 20 months and not reached, respectively [11, 12]. The most common side effects included headache (34\%), infection (41\%), diarrhea (25\%), and bleeding (25\%). There were only $4 \%$ of grade $\geq 3$ bleeding events and no events of atrial fibrillation.

Zanubrutinib is another irreversible BTK inhibitor with a similar mechanism of covalent cysteine 481 binding but very low activity towards ITK, TEC, and EGFR [20]. It was recently granted accelerated approval for the treatment of relapsed/refractory MCL based on two phase II studies $[15,21]$. Zanubrutinib was found to have an ORR of $84 \%$ in each of these studies, but the CR rate was different, with 59\% in the BGB-3111-206 study and $22 \%$ in the BGB-3111-AU-003 study. The discrepancy 
Table 1 BTK inhibitors in the treatment of relapsed/refractory MCL

\begin{tabular}{|c|c|c|c|c|c|c|c|c|}
\hline$\overline{\text { BTKi }}$ & $\begin{array}{l}\text { NCT\#/ } \\
\text { publication }\end{array}$ & Phase & $\begin{array}{l}\text { Sample size } \\
\left.\text { [median f/up }{ }^{*}\right]\end{array}$ & $\begin{array}{l}\text { Median lines of prior } \\
\text { therapy }\end{array}$ & $\begin{array}{l}\text { ORR\% } \\
\text { [CR\%] }\end{array}$ & $\begin{array}{l}\text { Median PFS } \\
\text { (months) }\end{array}$ & $\begin{array}{l}\text { \% bleeding events } \\
\text { [grade } \geq 3 \text { ] }\end{array}$ & $\begin{array}{l}\text { \% A.fib } \\
{[\text { grade } \geq 3]}\end{array}$ \\
\hline Ibrutinib & $\begin{array}{l}\text { NCT01236391 } \\
{[8,9]}\end{array}$ & $\|$ & $111[26.7]$ & 3 & $67[23]$ & 13 & $59[5]$ & $6[5]$ \\
\hline Ibrutinib & $\begin{array}{l}\text { NCT01646021 } \\
{[10]}\end{array}$ & III & $139^{\mathrm{a}}[20]$ & 2 & $72[19]$ & 14.6 & $10[8]$ & $4[4]$ \\
\hline Acalabrutinib & $\begin{array}{l}\text { NCT02213926 } \\
{[11-13]}\end{array}$ & $\|$ & 124 [15.2] & 2 & $81[40]$ & 20 & $33[2]$ & $0[0]$ \\
\hline Zanubrutinib & $\begin{array}{l}\text { NCT02343120 } \\
{[14]}\end{array}$ & $\mathrm{lb}$ & $43^{b}[10.3]$ & 1 & $90^{c}[20]$ & 18 & $30.2[7]$ & $4.7[\mathrm{NP}]$ \\
\hline Zanubrutinib & $\begin{array}{l}\text { NCT03206970 } \\
{[15]}\end{array}$ & $\|$ & $86[9]$ & 2 & 84 [59] & NR & $4.7[1.2]$ & $0[0]$ \\
\hline LOXO-305 & $\begin{array}{l}\text { NCT03740529 } \\
{[16]}\end{array}$ & । & $8[N P]$ & 3 & $37.5[0]$ & NP & $11[0]$ & $0[0]$ \\
\hline ARQ-531 & $\begin{array}{l}\text { NCT03162536 } \\
{[17]}\end{array}$ & I & $1[\mathrm{NP}]$ & NP & NP & NP & NP & NP \\
\hline
\end{tabular}

If more than one B cell malignancy was enrolled, responses are for the $\mathrm{MCL}$ patients in the trial. Adverse events were for all patients in the trial

Abbreviations: NR not reached, NP not presented, Btki Bruton's tyrosine kinase inhibitor, ORR overall response rate, CR complete response, PFS progression-free survival, A.fib atrial fibrillation

${ }^{\mathrm{a}}$ Number enrolled in BTKi arm only

b38 relapsed/refractory $M C L, 5$ patients were treatment naïve $\mathrm{MCL}$

${ }^{c}$ Relapsed/refractory MCL 88.9 [22.2], treatment naïve MCL, 100 [0]

*Median f/up in months

may be due to the higher rate of patients with low-risk disease in the BGB-3111-206 study (58\% versus 28\%) but more importantly due to the differences in response assessment (PET in the BGB-3111-206 versus CT in the BGB-3111-AU-003 study). A pooled analysis of the safety data from 424 patients treated with zanubrutinib showed the most common side effects to be upper respiratory tract infections (23.8\%), contusion (17.5\%), and diarrhea (14.2\%) [22]. Major hemorrhage and atrial fibrillation were seen in $2.1 \%$ and $1.9 \%$, respectively, rates lower than that seen with ibrutinib but comparable to acalabrutinib, consistent with their respective kinome profiles.

Although the response rates with single-agent BTK inhibitors are relatively high, approximately one third of patients display primary resistance to BTK inhibitors, and nearly all patients eventually progress (secondary resistance). The outcomes of patients who progress following BTK inhibitors are relatively poor with an ORR ranging between 25 and $42 \%$ and median OS between 6 and 10 months with salvage therapies [23-25]. There was no specific advantage of either bendamustine, cytarabine, or lenalidomide when given after progression on ibrutinib [23-25]. Mutational profiling was performed on 15 ibrutinib resistant patients demonstrating a mutation in BTK in only 2 patients (C481S and C481R) and no mutation in PLCG2, thus showing a distinct genetic mechanism of progression compared to the ibrutinib resistant chronic lymphocytic leukemia (CLL) patients [25]. In contrast, p53 mutations were found in $75 \%$ of patients while NSD2, a chromatin modifier gene, was mutated in $75 \%$ of cases that underwent blastoid transformation, suggesting their significance in ibrutinib resistance. The biology of ibrutinib resistance is currently an active area of investigation, and a full discussion is outside the scope of this review.

Novel BTK inhibitors are currently in clinical development that may have a significant role in the treatment of ibrutinib-resistant disease. LOXO-305 is a highly selective BTK inhibitor, which non-covalently binds to BTK unlike ibrutinib, acalabrutinib, and zanubrutinib that all act by covalent binding. This property gives LOXO-305 higher affinity and selectivity for BTK in addition to inhibition of the C481S mutant, although this is less relevant for MCL as it is for CLL as the C481S mutation rate is much lower in MCL as discussed previously. It is currently being evaluated in a phase $1 / 2$ BRUIN study enrolling patients with relapsed/refractory CLL and MCL with the patients in the MCL group receiving a median of 3 prior lines of therapy at the time of enrollment [26]. Preliminary results showed three responses in 8 patients with MCL, with two of these responders having prior progression on BTK inhibitor therapy, neither of which had a C481S mutation. The most common treatment-emergent adverse events (TEAEs) were fatigue (25\%), diarrhea (18\%), anemia (14\%), and rash (14\%). Only $11 \%$ of patients had a contusion, with no events of serious bleeding or atrial fibrillation.

ARQ-531 is a reversible multi-kinase inhibitor of not only BTK but Src, Syk, and Fyn, the last two of which have been previously shown to be relevant targets in MCL [27, 28]. Multi-faceted upstream kinase inhibition 
in the BCR pathway may enhance efficacy over downstream inhibition of BTK alone. ARQ-531 showed better survival compared to ibrutinib in the $\mathrm{E} \mu-\mathrm{TCL}$ and $\mathrm{E} \mu-$ TCL/c-myc transgenic mouse models of CLL and Richter's transformation, respectively [27]. Furthermore, ARQ-531 was able to inhibit the activation of the C481S BTK mutant as well as PLC 22 mutants in CLL cells. In a separate study, ARQ-531 was also able to deplete the levels of ERK, Myc, and MCL1 in preclinical models of AML showing an overall highly pleiotropic mechanism of action compared to other BTK inhibitors [29]. Thus, ARQ-531 may have activity against downstream mediators of ibrutinib-resistant MCL. However, further studies are needed specifically within ibrutinib resistant-MCL cells to provide more definitive evidence of its utility within this context.

Preliminary clinical results presented at the 2019 ASH conference show that ARQ-531 has activity in a variety of B cell malignancies that progressed on previous BTK inhibitors [17]. Preliminary safety data during the doseescalation phase showed that the most common TEAE were nausea $(10 \%)$, diarrhea (10\%), and fatigue (7.5\%). There were no atrial fibrillation or grade $3 / 4$ bleeding events noted in the study. As there was only one patient with MCL in this study, its activity in MCL awaits further evaluation in larger studies with more MCL patients. A phase $1 \mathrm{~b}$ expansion phase at $65 \mathrm{mg}$ daily is currently ongoing in multiple B cell malignancies including MCL.

\section{$B C L 2$ inhibitors}

The programmed cell death pathway plays an important role in MCL pathogenesis as $90 \%$ of MCL cases have been found to overexpress BCL2 [30]. BCL2 may protect MCL cells from apoptogenic signals that would otherwise cause programmed cell death. Venetoclax is a second-generation $\mathrm{BH} 3$ mimetic with higher selective inhibition of BCL2 over BCL-XL as compared to the first generation $\mathrm{BH} 3$ mimetic navitoclax, thus reducing the off-target effect of thrombocytopenia seen with BCL-XL inhibition while retaining strong BCL2 inhibition. Venetoclax was studied as a single agent in relapsed/refractory B cell NHL patients $(n=106)$ that included 28 patients with MCL [30]. A 3-week ramp-up dosing schedule was used which resulted in only three cases of laboratory tumor lysis syndrome (TLS) and no cases of clinical TLS. For the MCL cohort, the median PFS was 14 months (better than the other NHL subgroups) with a dose of $800 \mathrm{mg}$ sufficient to achieve a durable response. Although not FDA approved for relapsed/refractory $\mathrm{MCL}$, venetoclax is a valuable single-agent option and is currently undergoing investigation in combination therapies (as discussed later).
MCL1, another BCL2 family pro-survival protein, has also been found to be overexpressed in MCL although not at the same high frequency as BCL2, with one study reporting $33 \%$ of cases with increased MCL expression on IHC at a cutoff level of $>10 \%$ [31]. The MCL1specific inhibitor MIK665 has shown activity when studied as a single agent in MCL cell lines and patient samples and has shown significant synergism with venetoclax in several PDX models of MCL [32, 33]. MIK665 is currently being studied in phase I clinical trial of relapsed/refractory lymphoma and myeloma (NCT02992483).

\section{Proteasome inhibitors}

Proteasome inhibition causes MCL cell death through multiple mechanisms, including decreased NF-kappaB signaling by preventing degradation of IкB, cell cycle arrest by inhibiting $\mathrm{p} 27$ degradation, and reactive oxygen species generation $[34,35]$. Bortezomib is a reversible inhibitor of the $26 \mathrm{~S}$ proteasome that was the first FDAapproved therapy for relapsed/refractory MCL based on the results from the landmark PINNACLE trial [36, 37].

The second-generation irreversible proteasome inhibitor, carfilzomib induces apoptosis in MCL cell lines and primary samples through inhibition of NF-kappaB and Stat3 signaling [38]. Carfilzomib may have less neurotoxicity compared to bortezomib but at the risk of a higher rate of cardiotoxicity [39]. Carfilzomib was evaluated in phase II clinical trial of relapsed/refractory MCL but suffered from poor accrual with only 4 patients evaluated for treatment response, all of which progressed by three cycles of therapy [40]. Thus, bortezomib is the only proteasome inhibitor currently approved with proven single-agent activity in relapsed/refractory MCL. The potential of this therapeutic class likely resides in its use in combination treatments with other agents.

\section{Non-cellular immune therapies Lenalidomide}

Lenalidomide is a second-generation immunomodulatory agent with superior anti-tumor properties and better side effect profile compared to its analog, thalidomide, and thus has nearly supplanted it in cancer treatment. Lenalidomide showed significant activity in pre-clinical models of MCL through pleiotropic effects including direct cytotoxicity to malignant cells, enhancement of dendritic, NK and T cell activation, inhibition of survival signals provided by stromal support, and suppression of angiogenesis [41-43]. Of note, recent data suggests that angiogenesis is a significant prognostic factor in primary MCL, and SOX11 is an important driver of the angiogenic program, thus providing further importance to this well-established activity of lenalidomide in MCL [44]. 
Lenalidomide was studied as a single agent in relapsed/refractory NHL in the NHL-002, NHL-003, MCL-001 (EMERGE), and MCL-002 (SPRINT) trials and demonstrated modest single-agent activity in relapsed/refractory MCL in the pre-ibrutinib era [45-49]. The results of these trials have been extensively reviewed previously [50].

\section{Monoclonal antibodies}

Antibody engineering has been perhaps one of the greatest achievements in cancer therapeutics over the past two decades. The introduction of rituximab brought about significant improvements in responses and OS across all B cell NHL, including MCL. Despite this initial advancement, there has been limited progress even after the development of many uniquely designed antibodies with distinct targets with significant preclinical potential. Several antibodies targeting other markers expressed at a high frequency in MCL including ROR1, CD37, and CD74 are currently being evaluated in MCL.

Obinutuzumab is a glycoengineered type II antibody with increased antibody-dependent cytotoxicity (ADCC) due to enhanced binding to NK cells. Obinutuzumab showed enhanced cell killing of MCL cell lines compared to rituximab [51]. Although, it showed modest single-agent activity when studied in relapsed/refractory MCL (27\%); $20 \%$ of rituximab refractory patients demonstrated response [52]. Hence, several studies are ongoing using obinutuzumab as a combinatorial approach both in the upfront and relapsed/refractory settings as discussed elsewhere.

ROR1 is an oncoembryonic receptor tyrosine kinase and is only expressed in embryonic and malignant tissues, theoretically providing a much more specific target than the previously discussed surface proteins. It is expressed at a high level in CLL [53, 54] and MCL [55]. It is activated by the ligand Wnt5a and induces proliferation through activation of Rac1 and RhoA [56]. Cirtuzumab (UC-961) is a humanized antibody that targets ROR1 and blocks the binding of Wnt5a and activation of ROR1. Of note, it demonstrated preclinical activity against ibrutinib-resistant MCL [57]. In a study of relapsed/refractory CLL $(n=26), 17$ among the 22 evaluable patients who received cirtuzumab had stable disease with a median TTNT of 262 days [58]. This led to the phase Ib/II CIRLL trial (NCT03088878) in which cirtuzumab will be studied in combination with ibrutinib. This trial has separate cohorts of CLL and relapsed/refractory MCL. The MCL expansion cohort is currently underway, and preliminary results are eagerly awaited.

CD37 is expressed on normal and malignant B cells. Otlertuzumab is a humanized anti-CD37 antibody, which acts by triggering direct apoptosis by upregulating the pro-apoptotic BCL2 family member, Bim, in target cells. It was studied in a phase I study of patients with relapsed/refractory follicular lymphoma (FL), MCL, and Waldenstrom's macroglobulinemia [59]. A total of 16 patients were treated, 4 with MCL. Unfortunately, no activity was seen in MCL patients. However, as otlertuzumab was generally well tolerated, rationale combination studies may be feasible to improve on these results. It may be possible that the extent of Bim upregulation was not able to overcome the high rate of BCL2 overexpression seen in MCL and combining otlertuzumab with a BH3 mimetic, such as venetoclax, may offer much better responses. Antibody-drug conjugates (ADC) targeting CD37 is discussed below.

The anti-CD74 antibody milatuzumab showed a promising preclinical activity in MCL, especially when the surface expression of CD74 is enhanced by blocking receptor recycling [60]. In a phase I study where milatuzumab was given as monotherapy in relapsed/refractory NHL (one case of MCL) and CLL, 23 patients were enrolled, and 8 patients had stable disease with no CR or partial responses (PR) [61]. With the high rate of receptor endocytosis, CD74 may be a more attractive target for cytotoxic drug delivery. However, no further trials with milatuzumab or drug conjugated derivatives of milatuzumab are planned at present.

\section{Antibody-drug conjugates}

ADCs allow targeted delivery of a potent cytotoxic molecule which cannot be otherwise delivered by itself due to toxicity on off-target cells, thus resulting in a much better therapeutic window. Several ADCs have been developed with significant activity in B cell NHL but are still awaiting further studies in MCL.

CD79B is a receptor important in B cell development that is expressed in several subtypes of B cell NHL, including MCL. Polatuzumab vedotin is an anti-CD79B antibody conjugated to the mitotic poison monomethyl auristatin $\mathrm{E}$ (MMAE) that works by delivering auristatin $E$ into cells after cleavage of the antibody occurs after endocytosis of the polatuzumab/CD79B complex [62]. It was recently approved in DLBCL in combination with BR [63]. Currently, polatuzumab is being studied in several trials both in frontline and relapsed settings as a combinatorial approach (with chemotherapy or other novel agents) in DLBCL and FL. As of yet, no MCL specific trials are currently registered.

$\mathrm{CD} 22$ is an inhibitory component of the B cell receptor expressed early in $\mathrm{B}$ cell development at the pre- $\mathrm{B}$ cell stage as well as mature B lymphocytes but is lost upon differentiation into plasma cells. The expression of CD22 is nearly universal in MCL. Several ADCs targeting CD22 have been developed. Inotuzumab ozogamicin is a humanized IgG4 antibody targeting CD22 which is conjugated to the cytotoxic agent calicheamicin [64]. 
When calicheamicin is internalized, it binds to DNA causing double-stranded breaks and apoptosis. Inotuzumab is FDA-approved for the treatment of B cell precursor ALL. Although early phase clinical studies in relapsed/refractory B cell NHL have shown promise, a phase III study was discontinued early due to lack of efficacy [65]. Pinatuzumab vedotin is another anti-CD22 ADC that is conjugated to MMAE leading to microtubule inhibition upon internalization. In the phase II ROMULUS study, patients with relapsed/refractory DLBCL and FL were randomized to either rituximab plus pinatuzumab or rituximab plus polatuzumab [66]. Although both pinatuzumab + rituximab and polatuzumab + rituximab were associated with similar ORR $(60 \%$ vs $54 \%$ ) and CR (26\% vs $21 \%)$, polatuzumab was associated with a better duration of response (13.4 months vs 6.2 months) and OS (20.1 months vs 16.5 months). Thus, pinatuzumab was dropped from further development in favor of polatuzumab. Trph-222 is an anti-CD22 antibody conjugated to maytansine, a microtubule targeting compound, using an optimized site-specific protein modification technology [67]. It is currently in a phase I study in relapsed/refractory B cell lymphomas (NCT03682796).

Similar to CART cells and BiTe antibodies (discussed later), $\mathrm{ADCs}$ that target the ubiquitous B-lineage surface marker CD19 have been developed. Loncastuximab tesirine (ADCT-402) is a humanized anti-CD19 IgG1 conjugated to pyrrolobenzodiazepine (PDB) which is a DNA damaging agent. In a large phase I study $(n=88)$ of patients with relapsed/refractory B cell NHL, ADCT402, (at doses $\geq 120 \mathrm{ug} / \mathrm{kg}$ ) demonstrated an ORR of $59.4 \%(\mathrm{CR}$ rate $=40.6 \%)$ [68]. Of the 9 patients with MCL (all doses), an ORR was $44.4 \%$ and CR rate was $33.3 \%$, respectively. ADCT-402 was overall tolerable with the most common TEAE ( $\geq 20 \%$ ) being hematologic abnormalities, fatigue, edema, LFT abnormalities, fatigue, and dyspnea. These results led to three phase II clinical trials that are currently ongoing: ADCT-402 monotherapy in relapsed/refractory DLBCL (NCT03589469), ADCT-402 in combination with ibrutinib in relapsed/refractory DLBCL and MCL, and ADCT-402 in combination with durvalumab in relapsed/refractory DLBCL, MCL, and FL (NCT036855344). Two other anti-CD19 ADCs, coltaximab ravtansine and denintuzumab, were investigated but were not pursued further either due to limited efficacy or safety concerns [69-71].

Naratuximab emtansine (IMGN529) is an ADC linked to the maytansinoid DM1 which targets CD37 [72]. An initial phase I study shown a tolerable safety profile in relapsed/refractory B cell NHL [73]. It is currently being evaluated in a phase II trial in patients with relapsed/refractory B cell NHL in combination with rituximab (NCT02564744). Another anti-CD37 ADC, AGS67E, is also in clinical development. AGS67E is a human IgG2 antibody conjugated to MMAE. In a phase I trial of 50 patients with $\mathrm{B}$ and $\mathrm{T}$ cell NHL (only 2 patients with MCL), it demonstrated an ORR of $22 \%(C R$ rate $=11 \%)$ [74]. Expansion cohorts of DLBCL and cutaneous $\mathrm{T}$ cell lymphoma are ongoing.

The BTK inhibitors are now used extensively as a first-line treatment of relapsed/refractory $\mathrm{MCL}$ and the biology of BTK resistant MCL is quite different from BTK sensitive MCL, it is unclear if the response rates found in the earlier trials of bortezomib, lenalidomide, and the various antibody therapies can be extrapolated to the BTK resistant patients. Overall, it is highly unlikely that single-agent therapy (aside from cellular therapies, discussed later) will provide durable responses in this population and combination strategies will be needed to provide more meaningful responses.

\section{Combination therapy \\ Combinations of individually active agents}

Several past and ongoing single-arm studies are evaluating if the combination of therapies already known to have single-agent activity in MCL discussed above can prolong the PFS benefit of either agent alone (Table 2). While we may not be able to review every one of these trials, we will review those that have either excellent preclinical rationale or promising preliminary results. It is important to interpret these studies very carefully, especially when based on PFS alone, as it is difficult to conclude that combination therapy is more effective than their sequential use without a randomized comparison of these two approaches. This may be of less importance in BTK inhibitor combination studies given the overall lack of durable responses with therapies used after BTK resistance as discussed previously. Nonetheless, these studies will provide preliminary evidence for larger, welldesigned randomized clinical trials to confirm that combinations of active agents should become the standard in place of single-agent use.

The combination of ibrutinib and venetoclax has shown synergism in preclinical models of MCL with enhanced levels of dephosphorylation of substrates within the BTK pathway as well as a reduction in levels of antiapoptotic BCL2 family members [83]. A phase II study (AIM study) was conducted to evaluate this combination in relapsed/refractory MCL [76]. This study $(n=24)$ had an initial ibrutinib lead-in phase for one cycle followed by venetoclax ramp-up to $400 \mathrm{mg}$. The CR rate was $42 \%$ and $62 \%(n=23$ with relapsed/refractory MCL) based on CT and PET, respectively. Results of minimal residual disease (MRD) assessment showed a negativity frequency of $67 \%$ of the bone marrow by flow cytometry and $38 \%$ in the blood by PCR [76]. An amendment to the study allowed people to discontinue therapy if they achieved 
Table 2 Investigative combination treatments for relapsed/refractory MCL

\begin{tabular}{|c|c|c|c|c|c|c|c|}
\hline Combination therapy & $\begin{array}{l}\text { NCT\#/ } \\
\text { publication }\end{array}$ & Phase & $\begin{array}{l}\text { Sample size } \\
\left.\text { [median } \mathrm{f} / \mathrm{u}^{*}\right]\end{array}$ & $\begin{array}{l}\text { Median lines of } \\
\text { prior therapy }\end{array}$ & $\begin{array}{l}\text { ORR\% } \\
{[\text { CR\%] }}\end{array}$ & $\begin{array}{l}\text { Median PFS } \\
\text { (months) }\end{array}$ & Grade $\geq 3(\%)^{\mathbf{a}}$ \\
\hline Ibrutinib/rituximab & $\begin{array}{l}\text { NCT01880567 } \\
{[75]}\end{array}$ & $\|$ & $50[16.5]$ & 3 & $88[44]$ & NR & A.fib (12), renal and urinary disorder (6) \\
\hline Ibrutinib/ venetoclax & $\begin{array}{l}\text { NCT02471391 } \\
{[76,77]}\end{array}$ & $\|$ & $23[37.5]$ & 2 & $71[62]$ & 29 & $\begin{array}{l}\text { Diarrhea (12), soft tissue infection (8), lower respiratory tract } \\
\text { infection (8) TLS (8), a.fib (8) }\end{array}$ \\
\hline Ibrutinib/ venetoclax & NCT03112174 & III & ongoing & & & & \\
\hline $\begin{array}{l}\text { Obinutuzumab/ } \\
\text { ibrutinib }\end{array}$ & $\begin{array}{l}\text { NCT02558816 } \\
{[78]}\end{array}$ & । & $9[23.5]$ & 1 & $87[87]$ & NR & none \\
\hline $\begin{array}{l}\text { Obinutuzumab/ } \\
\text { ibrutinib/ venetoclax }\end{array}$ & $\begin{array}{l}\text { NCT02558816 } \\
{[78]}\end{array}$ & 1 & 12 [6.5] & 2 & $\begin{array}{l}66.6 \\
{[25]}\end{array}$ & NR & none \\
\hline $\begin{array}{l}\text { Lenalidomide/ } \\
\text { rituximab }\end{array}$ & $\begin{array}{l}\text { NCT00294632 } \\
\text { [79] }\end{array}$ & $\|$ & $44[23.1]$ & 2 & $57[36]$ & 11.1 & $\begin{array}{l}\text { Fatigue (14), non-neutropenic infection (7), hypercalcemia (7), } \\
\text { hyperuricemia (7) }\end{array}$ \\
\hline $\begin{array}{l}\text { Lenalidomide/ } \\
\text { rituximab }^{b}\end{array}$ & $\begin{array}{l}\text { NCT00783367 } \\
{[80]}\end{array}$ & $\|$ & $11[39.2]$ & 3 & $55[55]$ & 24.4 & Hypokalemia (10), hypophosphatemia (6) \\
\hline $\begin{array}{l}\text { Lenalidomide/ } \\
\text { obinutuzumab }\end{array}$ & NCT01582776 & $\|$ & $13[14.5]$ & 2 & $\begin{array}{l}46.2 \\
{[15.4]}\end{array}$ & NP & Infections (12.5) \\
\hline $\begin{array}{l}\text { lbrutinib/ } \\
\text { lenalidomide/ } \\
\text { rituximab }\end{array}$ & $\begin{array}{l}\text { NCT02460276 } \\
{[81]}\end{array}$ & $\|$ & $50[17.8]$ & 2 & $76[56]$ & 16 & Infections (26), rash (14), GI (12), vascular (10) \\
\hline Palbociclib/ibrutinib & $\begin{array}{l}\text { NCT02159755 } \\
{[82]}\end{array}$ & । & $27[25.6]$ & 1 & $67[37]$ & NP & $\begin{array}{l}\text { Hypertension (15), febrile neutropenia (15), lung infection (11), } \\
\text { URI (7), fatigue (7), transaminitis (7) rash (7) }\end{array}$ \\
\hline Palbociclib/ibrutinib & NCT03478514 & $\|$ & ongoing & & & & \\
\hline
\end{tabular}

Abbreviations: $N R$ not reached, $N P$ not presented, ORR overall response rate, $C R$ complete response, $P F S$ progression-free survival, $A$.fib atrial fibrillation

${ }^{a}$ Non-hematologic grade $\geq 3 \mathrm{AE}$ in $>5 \%$ of patients

${ }^{\mathrm{b}}$ Rituximab refractory

*Median f/up in months

MRD negativity. Updated analysis of this study was presented at the ASH 2019 conference, which showed a median PFS and OS of 29 months and 32 months, respectively, at a median follow-up of 37.5 months [77]. Of note, the median OS was increased compared to that reported for the single-agent ibrutinib study at 22.5 months [9]. Fifty percent of patients who harbored TP53 mutation (six of 12) responded, and among these, five had a response that extended out to a least 24 months. Of the five patients who obtained MRD negativity, four patients remained free of clinical or MRD progression while still being off therapy at the time of last follow-up $(6,13,17$, and 18 months). Thus, ibrutinib/venetoclax combination therapy may offer deeper and more durable responses to patients compared to monotherapy alone, even in the presence of TP53 mutations. Even more intriguing is the possibility of a limited course of therapy of ibrutinib/venetoclax to induce long-term durable remissions in certain patients. The phase III SYMPATICO study (NCT03112174), a randomized study of ibrutinib/ venetoclax versus ibrutinib alone, is currently ongoing. This study will establish whether ibrutinib should be given along with venetoclax or if venetoclax should be reserved until after progression while on ibrutinib.

Obinutuzumab counteracts venetoclax resistance by the reduction in NF-kappaB signaling leading to a reduction in BCL-XL levels in primary MCL cells [84]. This in addition to the known synergistic activity of ibrutinib and venetoclax as discussed above provides a significant rationale for the combination of obinutuzumab/ibrutinib/venetoclax which is currently being evaluated in the ongoing OASIS study [85]. This non-randomized study has three separate recruitment steps: obinutuzumab with ibrutinib in relapsed/refractory MCL (step A), obinutuzumab with ibrutinib and venetoclax in relapsed/refractory MCL (step B), and obinutuzumab with ibrutinib and venetoclax in newly diagnosed MCL (step C, discussed below). For steps B and C, venetoclax was added at cycle 2 with weekly ramp-up. In the relapsed/refractory MCL, both combinations were well tolerated with DLT not reached up to $800 \mathrm{mg}$ of venetoclax. In step A ( $n=9,2$ with blastoid MCL), $87 \%$ of patients were in CR and 67\% (4 of 6) of patients were MRD negative by PCR in the blood and bone marrow after cycle 6 . For step B ( $n=12,4$ with blastoid MCL), four patients had progressive disease during the first two cycles. Of nine patients assessed after cycle 6 , five were in CR and the MRD analysis is pending. These preliminary results established obinutuzumab/venetoclax/ibrutinib combination to be safe and these responses are promising, but larger studies will be needed to define if this combination provides better efficacy compared to the individual drugs or two-drug combinations in relapsed/refractory MCL.

As lenalidomide has potent immunomodulatory activity with the ability to activate antigen-presenting cells (APCs), there is a significant pre-clinical rationale for combinations with either rituximab or obinutuzumab to 
enhance the ADCC induced by these antibodies. Aside from this, lenalidomide may re-sensitize rituximab resistant cells. In a phase $1 / 2$ study of relapsed/refractory MCL patients, lenalidomide/rituximab demonstrated an ORR of $57 \%$ and a CR rate of $36 \%$, which were higher than lenalidomide monotherapy [79]. In another study, lenalidomide was given initially as a lead-in therapy for 2 months followed by concurrent lenalidomide/rituximab in rituximab refractory patients. The study aimed to test whether lenalidomide could re-sensitize the disease to rituximab [80]. In the 11 patients with MCL, an ORR of $55 \%(\mathrm{CR}$ rate $=36 \%)$ was seen after lenalidomide with no further responses after the addition of rituximab but with the 2 PR improving to CR to 55\% [80]. Lenalidomide/rituximab was further combined with ibrutinib in the Nordic phase 1/2 PHILEMON study with relapsed/ refractory MCL $(n=50)$ [81]. With a median follow-up of 17.8 months, ORR was $76 \%$ with a CR rate of $56 \%$. The lenalidomide/obinutuzumab was studied in relapsed/refractory B cell NHL, which included 13 patients with MCL and demonstrated an ORR of $39 \%$ and a CR rate of $23 \%$.

Although combination chemotherapy for second-line therapy is generally falling out of favor to more targeted therapies or clinical trial enrollment, there is one chemotherapy regimen worthy of mention in the relapsed/refractory setting. In a retrospective review of patients following progression on ibrutinib, R-BAC (rituximab/bendamustine/cytarabine) had an ORR of $83 \%$ (CR rate of $60 \%$ ) with a median PFS and OS of 10.1 months and 12.5 months, respectively [86]. Notably, $31 \%$ of patients were able to bridge to allo-HCT. Although responses were not durable, R-BAC may be a potentially valuable option for patients in need of cytoreduction before CART cell therapy or allo-HCT, especially in the setting of ibrutinib failure which often has a rapidly progressive course.

\section{Combination of active therapies with investigational agents}

Several investigational drugs have shown little or no clinical activity in MCL by themselves. However, strong preclinical evidence and rationale have led to clinical trials evaluating their use in combination with active therapies. A few notable ongoing clinical trials are discussed below.

\section{CDK4/6 inhibitors}

The $t(11: 14)$ is nearly universal in MCL and places cyclinD1 into the immunoglobulin locus resulting in overexpression of cyclinD1, thus leading to phosphorylation of retinoblastoma by CDK4/6 resulting in its inactivation and transition through the G1/S checkpoint. Thus, CDK inhibitors naturally arose as an extremely attractive rationale therapy for MCL. Interestingly, there is a preferential expression of CDK4 relative to CDK6 in MCL cells [87]. Of the specific CDK inhibitors currently, FDA approved, the CDK4 selective inhibitor palbociclib may have a more selective therapeutic benefit in MCL. In a phase $1 \mathrm{~b}$ study of relapsed/refractory MCL, palbociclib given as monotherapy $(n=17)$ demonstrated an ORR of $18 \%$ with $41 \%$ of patients having stable disease [88]. In patients who had a response, the median DOR was 18 months, suggesting a subset of MCL patients with high sensitivity to CDK4 inhibition. Pre-clinical studies on MCL cells showed that prolonged G1 arrest by palbociclib leads to the induction of the PI3K inhibitor, PIK3IP1, thus preventing downstream activation of the PI3K pathway from BTK, an important mechanism of ibrutinib resistance [89]. This led to a phase 1 study evaluating the safety of the palbociclib/ibrutinib combination in relapsed/refractory MCL [82]. In the study, the combination was tolerable with cytopenias (neutropenia [41\%] and thrombocytopenia [30\%]), febrile neutropenia $(15 \%)$, hypertension $(15 \%)$, and lung infection $(11 \%)$ being the most common grade $3 / 4$ toxicities The ORR and CR rate were $67 \%$ and $37 \%$, respectively, with a 2 year PFS of $59.4 \%$. Currently, there is an ongoing phase II trial using this combination in relapsed/refractory MCL (NCT02159755). Current or past clinical trials of other CDK inhibitors have been recently reviewed. Overall, the single-agent activity of these have been relatively mild and will likely require combination studies with other agents [87]. However, one particular mention is voruciclib, a broad CDK inhibitor (with activity to CDK1, 4, 6, in addition to CDK9), which is currently undergoing evaluation in early phase studies as monotherapy in B cell malignancies (NCT03547115). This drug showed increased activity with venetoclax in preclinical studies of DLBCL [90]. Thus, further studies of this combination in MCL is warranted.

\section{Cellular immune therapies CAR-T cell therapy}

CART therapy revolutionized the treatment landscape of relapsed/refractory DLBCL and B cell acute lymphoblastic leukemia (ALL) by providing durable responses to patients that had otherwise incurable disease. In the ZUMA-2 trial, the KTE-X19 product (axicabtagene ciloleucel) was tested in relapsed/refractory MCL patients [91]. Inclusion criteria included the failure of prior chemotherapy and anti-CD20 antibody therapy, and at least prior use of a BTK inhibitor, although a failure of BTK inhibitor therapy was not a requirement for enrollment. Bridging therapy was allowed as needed for disease stability during the manufacturing process with either steroids or a BTK inhibitor. In the intent to treat population $(n=74)$, the ORR was $85 \%$ (CR rate was 
59\%) with a median TTR of 1 month. At a median follow up of 12.3 months, $57 \%$ of patients were in remission with a 12 -month PFS and OS of $61 \%$ and $83 \%$, respectively. There was no specific risk factor that predicted a lack of response to therapy, although the numbers in the subgroup analysis were small. The rate of cytokine release syndrome (CRS) was $91 \%$ ( $15 \%$ grade $\geq 3$ ), and $63 \%$ had neurological events ( $31 \%$ grade $\geq 3$ ). Grade $\geq 3$ infections occurred in $32 \%$ of patients, and $26 \%$ of patients had grade 3 or higher cytopenias after 90 days from the infusion. Overall, the side effect profile was relatively similar to previously reported with prior CART trials $[92,93]$. Given the impressive results on this primary efficacy analysis, KTE-X19 is currently undergoing fast-track review by the FDA.

\section{BiTe antibodies}

BiTes are comprised of two distinct antibody chain combinations each able to recognize a different epitope, one with specificity for an epitope present on $\mathrm{T}$ cells and the other of which recognizes an epitope on the target cell of interest resulting in direct cell-mediated toxicity of the tumor cell [94]. Four BiTes have shown promising activity in relapsed/refractory B cell NHL, including MCL (Table 3).

The most advanced BiTe in clinical development for B cell malignancies is blinatumomab, an antibody that crosslinks B cells and T cells by ligating CD3 and CD19. In phase I trial of relapsed/refractory NHL $(n=76)$, blinatumomab demonstrated an ORR of $69 \%$ and a CR rate of $37 \%$ [95] with durable responses in some patients on long-term follow-up [96]. Of note, patients with relapsed/refractory MCL $(n=24)$ had a higher ORR compared to DLBCL (71\% versus 55\%, respectively) [95]. The most significant toxicity was neurological events with 13 patients discontinuing treatment due to grade 3 or higher events. Blinatumomab is currently undergoing evaluation in combination with other therapies
(NCT02811679, NCT03072771,

NCT02568553, NCT03340766, and NCT03605589).

Mosunetuzumab is another BiTe in clinical development for B-NHL that ligates CD3 and CD20. Results of the ongoing phase $1 / 1 \mathrm{~b}$ dose-escalation study were presented at the 2019 ASH conference [97]. The trial enrolled 270 patients, including 23 patients with MCL. Of note, 30 patients had prior CART therapy. Mosunetuzumab was given once every 21 days (after initial weekly dosing during the first cycle) for 8 cycles, with the continuation of therapy for patients with a PR or stable disease after the 8 cycles to a maximum of 17 cycles. CRS occurred in $28.9 \%$ of patients $(n=3$, grade $\geq 3)$ and neurotoxicity in $43.7 \%$ of patients $(n=1$, grade $\geq 3)$. Among 124 evaluable patients, ORR was $37.1 \%$ with a CR rate of $19.4 \%$, with 17 patients (13.7\%) remaining in CR after 16 months of treatment. MCL-specific response rates were not reported. In patients that had prior CART therapy, the ORR was $38.9 \%$ (CR rate $=22 \%$ ). Thus, mosunetuzumab demonstrated activity in a heavily pretreated population with a lower rate of CRS or neurotoxicity seen previously with CART or blinatumomab. These results are encouraging, and further studies with combination treatments may prolong the durability of responses.

REGN1979, a CD20/CD3 BiTe, is an IgG4 antibody that is modified to reduce binding to the Fc receptor has been studied in relapsed/refractory B cell NHL. The results of the phase I study were recently reported at the 2019 ASH conference [98]. REGN1979 was given every week for a total of 12 weeks followed by biweekly dosing for 12 more doses. Ninety-six patients (6 with MCL) were enrolled, 12 patients with prior CART. The CRS rate was $57 \%$ ( $n=7$ with grade $\geq 3$ ). Grade 3 or higher neurotoxicity occurred in two patients. The trial was suspended temporarily due to a patient's death from TLS for the protocol amendment. Responses were evaluated over a broad range of dosages with dosagedependent responses seen. With treatment $\geq 80 \mathrm{mg}$, the

Table 3 BiTes currently in trials

\begin{tabular}{|c|c|c|c|c|c|c|c|c|}
\hline BiTe & $\begin{array}{l}\text { NCT\#/ } \\
\text { publication }\end{array}$ & Route/administration schedule & Phase & $\begin{array}{l}\text { Sample size* } \\
\text { [follow-up**] }\end{array}$ & $\begin{array}{l}\text { Median lines } \\
\text { of prior } \\
\text { therapy }\end{array}$ & $\begin{array}{l}\text { ORR\% } \\
\text { [CR\%] }\end{array}$ & $\begin{array}{l}\text { CRS } \\
\text { [grade } \\
\geq 3 \text { ] }\end{array}$ & $\begin{array}{l}\text { Neurotoxicity } \\
\text { [grade } \geq 3 \text { ] }\end{array}$ \\
\hline Blinatumomab & $\begin{array}{l}\text { NCT00274742 } \\
{[95,96]}\end{array}$ & IV continuous infusion over 4 or 8 weeks & I & $24[5.2]$ & 3 & $\begin{array}{l}71.1^{\mathrm{a}} \\
{[42.8]}\end{array}$ & NP [NP] & $71[22]$ \\
\hline Mosunetuzumab & $\begin{array}{l}\text { NCT02500407 } \\
{[97]}\end{array}$ & IV once every 21 days & $\mathrm{l} / \mathrm{lb}$ & $23[\mathrm{NP}]$ & 3 & $\begin{array}{l}N P \\
{[N P]}\end{array}$ & $\begin{array}{l}28.9 \\
{[1.4]}\end{array}$ & $43.7[3.2]$ \\
\hline REGN1979 & $\begin{array}{l}\text { NCT03888105 } \\
{[98]}\end{array}$ & $\begin{array}{l}\text { IV weekly for } 12 \text { weeks, then every } 2 \\
\text { weeks for } 24 \text { weeks }\end{array}$ & 1 & $6[\mathrm{NP}]$ & 3 & $\begin{array}{l}N P \\
{[N P]}\end{array}$ & $57[7.2]$ & NP [3.1] \\
\hline GEN3013 & $\begin{array}{l}\text { NCT03625037 } \\
{[99]}\end{array}$ & $\begin{array}{l}\text { Subcutaneous weekly: cycle 1-2; every } 2 \\
\text { weeks cycle 3-6; every } 28 \text { days thereafter }\end{array}$ & $|/| \mid$ & NP & 3 & $\begin{array}{l}N P \\
{[N P]}\end{array}$ & $50[0]$ & $0[0]$ \\
\hline
\end{tabular}

Abbreviations: $N R$ not reached, NP not presented, ORR overall response rate, $C R$ complete response, $P F S$ progression-free survival, $C R S$ cytokine release syndrome ${ }^{a}$ Response rate at the target dose of $\geq 60 \mathrm{ug} / \mathrm{m}^{2} /$ day ( $n=7 \mathrm{MCL}$ patients)

*The sample size denotes only MCL patients

**f/up in months 
DLBCL cohort demonstrated an ORR of $57.9 \%$ (CR rate $=42.1 \%$ ), with CRs seen in post CART patients, while the FL cohort demonstrated an ORR of $95.5 \%$ (CR rate $=77.3 \%$ ) with $\geq 5 \mathrm{mg}$. These impressive response rates in heavily pre-treated patients may be at a tradeoff with the higher CRS rate seen with this BiTe compared to mosunetuzumab, but larger patient numbers treated at the RP2D will be needed for a more accurate comparison with the other BiTes. A global phase II study is currently planned enrolling relapsed/refractory NHLs including MCL.

GEN3013, a CD20/CD3 BiTe, is an IgG1 antibody that is unique in that it is administered subcutaneously rather than IV [100]. In pre-clinical models, subcutaneous administration demonstrated similar bioavailability and B cell depletion as IV administration, but with lower plasma cytokine levels and was hypothesized to result in less CRS but with the same responses in patients [100]. The preliminary results of a dose-escalation study on 18 patients with relapsed/refractory NHL $(n=14$ with DLBCL), were presented at the 2019 ASH conference [99]. Patients were treated weekly for two 28-day cycles followed by every 2 weeks for 4 cycles, then monthly until toxicity or progression. The CRS rate was $50 \%$ but none with grade $\geq 3$ and no patients had neurologic symptoms. There was a patient with a CR at a dose of $120 \mu \mathrm{g}$, with no DLTs yet with escalation still ongoing. A phase II trial is planned once the recommended phase II dosage RP2D is found.

\section{Current approaches to the upfront treatment of MCL}

A vast majority of the current studies that aim to improve upfront therapy in the fit patient involve the incorporation of targeted agents already known to have activity in the relapsed/refractory. These agents include ibrutinib, lenalidomide, or bortezomib that are incorporated into either the induction phase, maintenance phase, or both phases of treatment (Table 4). One of the main goals of these approaches is to deepen the responses achieved with chemotherapy and thereby achieving more durable remissions. This is extremely important in the younger MCL patient as the relapsed disease becomes much harder to treat with a lower chance of durable response with available therapies aside from allogeneic SCT. Another important goal is to decrease or eliminate the amount of cytotoxic chemotherapy administered upfront without compromising the response rates and long-term outcomes. In this section, we will first review the past and ongoing upfront novel treatment approaches in the young, fit patient followed by the older, transplant-ineligible patient. We will then discuss the exciting new approach of risk-adapted therapy particularly as it relates to the upfront treatment of MCL.

\section{Upfront treatment approaches for the transplant eligible patient}

\section{Bortezomib in frontline therapy}

Incorporation of bortezomib into the upfront setting has been studied extensively in multiple trials as part of induction chemotherapy, as part of the auto-HCT conditioning regimen, and as maintenance therapy following auto-HCT. A phase II study evaluated the outcomes following the addition of bortezomib during both alternating courses of the hyper-CVAD regimen [101]. After a follow-up of 44 months, the median time to treatment failure (TTF) was 55 months, which was comparable to the median TTF of hyper-CVAD alone at 56.4 months from a previous study, thus showing no improvement in the long-term outcomes of the addition of bortezomib to hyperCVAD in the upfront setting.

Incorporation of bortezomib into the BCNU/cytarabine/etoposide/melphalan (BEAM) preparative regimen (V-BEAM) before auto-HCT was studied in a phase $1 / 2$ study of B cell NHL patients $(n=42)$ with most MCL being the most common histology $(n=23)$ [102]. The PFS was not significantly different among the MCL patients who received V-BEAM relative to BEAM (historical control) in CR1; however, there was an increased incidence of autonomic dysfunction and ileus noted in the study.

Two separate trials looked at the benefit of bortezomib in maintenance therapy. The phase II CALGB 50403 studied two different bortezomib dosing strategies in a randomized fashion in the maintenance setting following induction chemotherapy and auto-HCT [110]. One arm received bortezomib at $3 \mathrm{mg} / \mathrm{m}^{2}$ IV on days $1,3,8$, and 11 of a 21-day cycle for 4 cycles, and the other arm received $6 \mathrm{mg} / \mathrm{m}^{2}$ IV four times weekly every 8 weeks for 18 months. At the 8-year follow-up, there was no PFS benefit in those receiving bortezomib maintenance compared to the historical control data (CALGB 59909); however, a PFS benefit could be seen when comparing these two populations from the time of transplant [103]. In addition, PFS was not significantly different between the maintenance and consolidative arms of the CALGB 50403 trial [103]. In the European MCL HAVON 75 MCL trial, patients were randomized to either no further treatment or bortezomib $1.3 \mathrm{mg} / \mathrm{m}^{2}$ given IV every 2 weeks for 2 years following induction chemotherapy and auto-HCT. There was no significant difference in the EFS or OS at 5 years between the two groups [104, 105]. Thus, taking these studies together, there is currently no clearly defined role of bortezomib in the upfront treatment of the young fit patient with MCL. 
Table 4 Investigative front line treatments for the newly diagnosed transplant eligible MCL patients

\begin{tabular}{|c|c|c|c|c|c|c|}
\hline Therapy & $\begin{array}{l}\text { NCT\#/ } \\
\text { publication }\end{array}$ & Phase & $\begin{array}{l}\text { Sample } \\
\text { size } \\
\text { [follow- } \\
\left.\text { up }^{*}\right]\end{array}$ & $\begin{array}{l}\text { ORR\% } \\
{[C R \%]}\end{array}$ & $\begin{array}{l}\text { Median } \\
\text { PFS }\end{array}$ & Grade $\geq 3(\%)^{\mathbf{a}}$ \\
\hline R-HyperCVAD+ bortezomib & [101] & $\|$ & $95[44]$ & $\begin{array}{l}100 \\
{[82]}\end{array}$ & 55 & Neutropenic fever (9) \\
\hline v-BEAM & [102] & $|/| \mid$ & $23[58.5]$ & $\begin{array}{l}95 \\
{[86]^{\mathrm{b}}}\end{array}$ & NR & $\begin{array}{l}\text { Neutropenic fever (59), anorexia (21), } \\
\text { peripheral neuropathy (19), } \\
\text { orthostatic hypotension (16), ileus (9) }\end{array}$ \\
\hline $\begin{array}{l}\text { Maintenance bortezomib days } 1,4,8,11 \text { of } 21 \text { days } \times 4 \\
\text { cycles vs. maintenance bortezomib weekly for } 4 \text { weeks } \\
\text { on } / 4 \text { weeks off } \times 9 \text { cycles }\end{array}$ & $\begin{array}{l}\text { NCT00310037 } \\
{[103]}\end{array}$ & III & $151^{\mathrm{c}}[96]$ & - & $\begin{array}{l}106.8 \mathrm{~V} \\
\mathrm{NR}\end{array}$ & $N P^{d}$ \\
\hline $\begin{array}{l}\text { Maintenance bortezomib every } 2 \text { weeks } \times 2 \text { years vs } \\
\text { observation }\end{array}$ & {$[104,105]$} & III & $\begin{array}{l}135^{\mathrm{e}} \\
{[77.5]}\end{array}$ & - & $\begin{array}{l}\text { NR } \vee \\
\text { NR }\end{array}$ & Infections (7) \\
\hline Lenalidomide $+\mathrm{R}-\mathrm{CHOP} \rightarrow \mathrm{R}-\mathrm{HIDAC} \rightarrow \mathrm{R} 2$ & NCT02633137 & $\|$ & ongoing & & & \\
\hline Maintenance R2 vs rituximab & NCT02354313 & III & ongoing & & & \\
\hline R2 & $\begin{array}{l}\text { NCT01472562 } \\
{[106,107]}\end{array}$ & $\|$ & 38 [64] & $\begin{array}{l}92 \\
{[64]}\end{array}$ & NR & $\begin{array}{l}\text { Infections (19.4), tumor flare (11), } \\
\text { abdominal pain (5), serum sickness } \\
\text { (5), syncope (5), neutropenic fever (5) }\end{array}$ \\
\hline $\begin{array}{l}\text { (R-CHOP/R-DHAP } \rightarrow \text { auto-HCT) vs (R-CHOP/R-DHAP }+ \\
\text { ibrutinib } \rightarrow \text { auto-HCT } \rightarrow \text { ibrutinib) vs (R-CHOP/R-DHAP } \\
+ \text { ibrutinib } \rightarrow \text { ibrutinib) }\end{array}$ & $\begin{array}{l}\text { NCT02858258 } \\
{[108]}\end{array}$ & III & ongoing & & & \\
\hline Acalabrutinib + BR/R-HiDAC $\rightarrow$ auto-HCT & NCT03623373 & $\|$ & ongoing & & & \\
\hline Ibrutinib + Rituximab $\rightarrow$ R-hyperCVAD & $\begin{array}{l}\text { NCT02427620 } \\
{[109]}\end{array}$ & $\|$ & $131[22]$ & $\begin{array}{l}100 \\
{[94]^{f}}\end{array}$ & NR & Fatigue (8), myalgia (8), rash $(8)^{\mathrm{g}}$ \\
\hline
\end{tabular}

Abbreviations: NR not reached, NP not presented, ORR overall response rate, $C R$ complete response, $P F S$ progression-free survival, auto-HCT autologous hematopoietic cell transplantation, $R 2$ lenalidomide (Revlimid) and rituximab

${ }^{a}$ Non-hematologic grade $\geq 3 \mathrm{AE}$ in $>5 \%$ of patients

${ }^{\mathrm{b}}$ Response measured at 100 days post-transplant

${ }^{\mathrm{c}}$ Number of patients enrolled start of induction, 50 patients were randomized to a twice-weekly schedule and 52 patients to a weekly schedule

${ }^{\mathrm{d}}$ Specific toxicities were not presented, but 19 patients withdrew from the study due to AE ( $28 \%$ of patients in a twice-weekly schedule and $13 \%$ in the weekly schedule) including 4 treatment-related deaths

e $44 \%$ of patients initially enrolled went on to randomization

${ }^{f}$ Response rate after completing both parts of the treatment. The ORR\% after completing ibrutinib + rituximab was 95

${ }^{9} \mathrm{AE}$ reported for the ibrutinib + rituximab part of therapy

*f/up in months

\section{Lenalidomide in frontline therapy}

Unlike bortezomib, lenalidomide is more difficult to administer with aggressive chemotherapy regimens due to the overlapping myelotoxicity of these therapies. Although most studies have incorporated lenalidomide with less myelosuppressive regimens in older patients, there have been some trials of lenalidomide in combination with chemotherapy in the upfront therapy in younger patients. An ongoing single institutional phase II trial (NCT02633137) incorporates lenalidomide into both induction and maintenance by initially giving lenalidomide with R-CHOP (Len-R-CHOP) for 4 cycles followed by consolidation with 2 cycles of rituximab and high-dose ara-C (R-HiDAC) followed by a maintenance phase of lenalidomide and rituximab (R2) for a total of 6 cycles. Of note, this study does not include an auto$\mathrm{HCT}$ and thus reduces the overall intensity and amount of chemotherapy delivered.

Given the overall comparable efficacy of R2 as compared to combination chemotherapy in FL in the
RELEVANCE trial [111] and its activity in relapsed/ refractory MCL $[79,80]$, this combination was studied in an upfront phase II trial which included young patients with low or intermediate risk MIPI scores and unfit patients with higher MIPI scores $[106,112]$. Both induction and maintenance phases were included in this trial, and patients received R2 therapy until disease progression. At a median follow-up of 64 months $(n=38)$, the 3 -year PFS and OS were $80 \%$ and $90 \%$, respectively [106]. Thus, R2 may be a potential option for the young patient with a less aggressive disease but a larger randomized study with a direct comparator arm is needed within this patient subset to make conclusions that are more firm on upfront R2 in treatment in MCL. The relative benefit of $\mathrm{R} 2$ compared to rituximab alone in the maintenance setting after induction chemotherapy, and auto-HCT is currently undergoing evaluation in the Italian phase III MCL0208 study (NCT02354313). 


\section{BTK inhibitors in frontline therapy}

Given the significant activity of BTK inhibition in relapsed/refractory MCL, approaches trying to incorporate ibrutinib into the front line setting are ongoing. The TRIANGLE study is a large phase III study by the European MCL network for young (age < 65), transplant eligible MCL patients, which incorporates ibrutinib in induction and maintenance therapy [108]. In the study, the patients were randomized into three separate arms: one arm received induction chemotherapy ( $\mathrm{R}-\mathrm{CHOP}$ alternating with R-DHAP for 6 cycles) followed by autoHCT (either BEAM or THAM conditioning, randomized by site), a second arm received the same regimen as arm 1 with the addition of ibrutinib during induction (only to R-CHOP cycles on days 1-19) and maintenance therapy (560 mg for 2 years), and the final arm received the same regimen as in the second arm but these patients will not undergo an auto-HCT. Rituximab could be added to any of these arms at the discretion of the treating physician. The primary outcome was the investigator-assessed failure-free survival (FFS). MRD assessment was also incorporated into the trial as an exploratory endpoint but was not used to guide treatment decisions as in ECOG 4151 (discussed below). As of July 2019, 511 patients have been randomized. In the completed safety run-in of the initial 50 patients, the feasibility of the two experimental arms was confirmed with no major differences in hematological and other toxicities and no major delays during induction. This trial will ultimately address whether incorporating ibrutinib into frontline chemotherapy provides a more durable response in MCL and whether auto-HCT adds any further benefit if ibrutinib is incorporated into frontline treatment. One U.S. group is evaluating the addition of acalabrutinib to the front line setting in transplant eligible patients by incorporating acalabrutinib into BR and alternating this with cycles of cytarabine and rituximab as induction chemotherapy before transplant (NCT03623373).

The MD Anderson group is currently pursuing a distinct chemo-sparing approach utilizing ibrutinib in the upfront treatment. In a phase II study (NCT02427620), ibrutinib was initially given with rituximab (part A) instead of concurrently with chemotherapy in newly diagnosed MCL patients until disease progression or an overall response was achieved. This was followed by consolidation with R-hyperCVAD/R-MTX without ibrutinib (part B) for 4 cycles. In the preliminary analysis presented at the 2019 malignant lymphoma meeting in Lugano, the ORR $(n=50)$ was $100 \%(C R$ rate $=90 \%)$ after a median of 6 cycles of part A [109]. MRD assessment of the bone marrow by flow cytometry at the time of best response showed an impressive negativity rate of $91 \%$. Few patients had grade $3-4$ toxicities during part A
(4\% myelosuppression and $8 \%$ fatigue). At a median follow-up of 36 months, 3-year PFS and OS were 89\% and $100 \%$, respectively. These results show that ibrutinib with rituximab is highly active in the treatment of naive patient with the potential to reduce the amount of cytotoxic chemotherapy delivered in the frontline setting.

\section{Novel upfront approaches for the transplant-ineligible patient}

Just as in the transplant-eligible patient, several trials are incorporating newer targeted agents into the upfront setting in transplant eligible patients (Table 5).

\section{Approaches for the unfit patient which include chemotherapy}

In the Nordic MCL4 (LENA-BERIT) study, treatment naïve elderly patients $(>65)$ or younger patients unfit for chemotherapy were treated with BR in addition to lenalidomide for a total of 6 cycles followed by maintenance lenalidomide for a total of 7 cycles. The MTD of lenalidomide with BR was found to be $10 \mathrm{mg}$ with lenalidomide started at the second cycle of treatment due to high rate toxicity when started concurrently with BR. In the study $(n=50)$, the ORR was $80 \%(C R$ rate $=64 \%)$ with $56 \%$ MRD negativity after BR-lenalidomide (and no increase in MRD negativity after maintenance therapy) [113]. Grade 3 or higher infections were found in $42 \%$ of patients with opportunistic infections in three patients (two cases of PJP and one case of CMV retinitis), likely due to the significant lymphosuppression from the bendamustine and lenalidomide combination. The high rate of infectious complications in this trial dampened enthusiasm for using this combination. R-CHOP with lenalidomide may have a more tolerable toxicity profile with less lymphosuppression and is currently under investigation (NCT02633137).

An ongoing phase III European R2 Elderly study is evaluating the benefit of lenalidomide given in the maintenance setting. This is a trial with a $2 \times 2$ factorial design in which patients are first randomized to either alternating cycles of R-CHOP and R-HAD (rituximab with high-dose ara- $\mathrm{C}$ and dexamethasone), each for $3 \mathrm{cy-}$ cles versus 8 cycles of R-CHOP with each arm being further randomized to either maintenance rituximab or maintenance rituximab with lenalidomide for two years. ECOG 1411 is another phase III trial evaluating maintenance lenalidomide in older patients. This trial also has a $2 \times 2$ factorial design in which patients are initially randomized to $\mathrm{BR}$ with or without bortezomib followed by randomization of each arm to maintenance rituximab with lenalidomide versus rituximab monotherapy for two years. The results of both these studies will define the role of maintenance lenalidomide when given after 
Table 5 Investigative front line treatment for the newly diagnosed transplant-ineligible MCL patients

\begin{tabular}{|c|c|c|c|c|c|c|}
\hline Therapy & NCT\#/publication & Phase & $\begin{array}{l}\text { Sample size } \\
\text { [follow-up*] }\end{array}$ & $\begin{array}{l}\text { ORR\% } \\
\text { [CR\%] }\end{array}$ & $\begin{array}{l}\text { Median } \\
\text { PFS (mos) }\end{array}$ & Grade $\geq 3(\%)$ \\
\hline $\mathrm{BR}+$ lenalidomide $\rightarrow$ lenalidomide & NCT00963534 [113] & $|/| \mid$ & $51[31]$ & $80[64]$ & 42 & $\begin{array}{l}\text { Infection (42), rash (18), allergic } \\
\text { reaction (12), mucositis (6), } \\
\text { musculoskeletal pain (6), anorexia (6) }\end{array}$ \\
\hline $\begin{array}{l}\text { (R-CHOP/R-HAD X } 4 \text { vs R-CHOP X 8) } \geq \\
\text { (R2 vs rituximab) }\end{array}$ & NCT01865110 & III & Ongoing & & & \\
\hline $\begin{array}{l}\text { (BR vs } B R+\text { bortezomib }) \rightarrow(\text { R2 vs } \\
\text { rituximab) }\end{array}$ & NCT01415752 & $\|$ & Ongoing & & & \\
\hline (BR + ibrutinib $\rightarrow$ rituximab + ibrutinib) & NCT01776840 & III & Ongoing & & & \\
\hline $\mathrm{BR}+$ acalabrutinib vs $\mathrm{BR}$ & NCT02972840 & III & Ongoing & & & \\
\hline $\mathrm{BR}+$ venetoclax & NCT03834688 & $\|$ & Ongoing & & & \\
\hline Bendamustine/obinutuzumab/venetoclax & NCT03872180 & $\|$ & Ongoing & & & \\
\hline Ibrutinib + rituximab & NCT01880567 & $\|$ & $49[28]$ & $98[60]$ & NR & $\begin{array}{l}\text { Myalgias (14), fatigue (14), } \\
\text { dyspnea (10), a.fib (8) }\end{array}$ \\
\hline R2 & NCT01472562 [106, 107] & $\|$ & $38[64]^{a}$ & $92[64]$ & NR & $\begin{array}{l}\text { Infections (19.4), tumor flare (11), } \\
\text { abdominal pain (5), serum sickness (5), } \\
\text { syncope (5), neutropenic fever (5) }\end{array}$ \\
\hline Acalabrutinib + R2 & NCT03863184 & $\|$ & ongoing & & & \\
\hline Venetoclax + ibrutinib + obinutuzumab & NCT02558816 ${ }^{\mathrm{b}}[85]$ & । & $15[N P]$ & $100[47]$ & NP & Hepatobiliary disorder (27), rash (7) \\
\hline $\begin{array}{l}\text { Acalabrutinib + rituximab }+ \\
\text { (bendamustine or venetoclax) }\end{array}$ & NCT02717624 & । & ongoing & & & \\
\hline
\end{tabular}

Abbreviations: NR not reached, NP not presented, ORR overall response rate, CRR complete response, PFS progression-free survival, A.fib atrial fibrillation, $R 2$ lenalidomide (Revlimid) and rituximab, $R$-HAD rituximab, cytarabine, dexamethasone

${ }^{a}$ Results are for both younger patients with low and intermediate MIPI scores and older patients with all MIPI scores; results for specific for older patients were not presented

${ }^{\mathrm{b}}$ Step $\mathrm{C}$ of the OAsls trial

*f/up in months

different chemoimmunotherapy regimens in elderly patients with MCL.

Currently, the ibrutinib and acalabrutinib are both being evaluated in combination with BR in two phase III randomized trials. Unlike the combination of $\mathrm{R}-\mathrm{CHOP}$ and ibrutinib which may be difficult to tolerate in the older patient as discussed previously, the combination of BR with ibrutinib was found to be safe with no doselimiting toxicities in a phase $1 / 1 \mathrm{~b}$ study of $\mathrm{R} / \mathrm{R}$ NHL which included older patients [114]. In the study, the ORR was $94 \%(C R$ rate $=76 \%)$ in relapsed $/$ refractory MCL patients $(n=17)$, thus demonstrating the potential efficacy of combined BTK inhibition with immunotherapy. The SHINE study (NCT01776840) will compare the combination of ibrutinib with BR followed by ibrutinib and rituximab (IR) maintenance versus $\mathrm{BR}+$ rituximab maintenance. There is another study (NCT02972840) looking at the combination of acalabrutinib and BR but will not include maintenance acalabrutinib.

Clinical trials with venetoclax incorporated into BR for the older population are also ongoing. An initial dosefinding study of venetoclax on a continuous schedule with BR in NHL of mixed histologies initially established a dosage of $800 \mathrm{mg}$ given continuously to be safe [115].
However, a subsequent FL study that included three separate arms (venetoclax $800 \mathrm{mg}$ and rituximab, venetoclax $800 \mathrm{mg}+\mathrm{BR}$, and BR alone) demonstrated a high rate of grade 3-4 AE (78\%) [116]. As both these trials enrolled both younger and older patients, this dosing was expected to lead to excessive toxicity in the older population. Thus, the ongoing phase II single-arm study (PrE0405) evaluating BR with venetoclax in patients 60 years and older is using dosing of $400 \mathrm{mg}$ given 10 days starting on day 1 of BR [117]. Finally, the combination of venetoclax/bendamustine/obinutuzumab is currently being investigated for older patients in the upfront setting (NCT03872180).

\section{Chemotherapy free approaches for the transplant- ineligible patient}

As discussed previously, IR has shown impressive activity in the upfront setting in younger patients [109]. Not surprisingly, this combination has also shown promising results for elderly untreated patients [118]. In a phase II study enrolling patients $\geq 65$ with untreated MCL, patients received continuous IR with rituximab initially given monthly for 8 cycles followed by every 2 months until disease progression [118]. At a median follow-up of 
28 months $(n=49), 61 \%$ were still on therapy with a relatively high number of patients discontinuing treatment due to atrial fibrillation $14 \%$ ), although $22 \%$ of patients enrolled had a prior history of atrial fibrillation. Among the evaluable patients $(n=42)$ the ORR was 98\% (CR rate $=60 \%)$ and median PFS was not reached. Thus, IR has high activity in the front line setting for elderly patients, although those with cardiac comorbidities should be monitored closely.

R2 was studied in untreated young MCL patients with a low-risk disease with low/intermediate MIPI score as well as elderly transplant-ineligible patients $[106,107]$. The elderly patients (> 60 years) comprised $63 \%$ of the study population. Although a subset analysis of older patients was not performed due to the small sample size, it is notable that at 5-year follow-up, patients with high MIPI scores (which only included older patients) had a similar PFS as low/intermediate-risk patients $(p=0.82)$. This suggests that R2 may be as active in the high-risk older patient as the low-risk younger patient [106]. R2 with acalabrutinib (ALR) is currently undergoing investigation in a phase II trial of untreated MCL which includes older patients (NCT03863184).

The combination of venetoclax/ibrutinib/obinutuzumab is currently undergoing evaluation in the OASIS study that is enrolling both relapsed/refractory and newly diagnosed MCL. Preliminary results of the newly diagnosed cohort $(n=15)$ have recently been reported [85]. Venetoclax was given at $400 \mathrm{mg}$ continuously after a cycle 1 ramp-up phase. Five patients had nonhematologic grade 3-4 toxicity including elevated LFTs and rash, and two patients had grade 3-4 hematologic toxicity. Seven patients went on to complete 6 cycles, all were in $\mathrm{CR}$ with no MRD. A multi-institutional trial with the combination of acalabrutinib/venetoclax/rituximab in treatment naïve MCL (along with a separate arm with treatment naïve and relapsed/refractory MCL receiving $\mathrm{BR}$ and acalabrutinib) is ongoing (NCT02717624).

\section{Risk-adapted approaches in $\mathrm{MCL}$-are we there yet?}

A risk-adapted approach involves the evaluation of data obtained during interim assessments to make ongoing changes to the therapeutic plan to tailor the amount or type of therapy to achieve the most optimal long-term response with the least toxicity. It is different from typical clinical decision making in that specific pre-set rules are in place before starting any therapy to guide the clinician down a predetermined therapeutic path. The interim assessment can be imaging studies such as PET or the presence of MRD. MRD is defined as detectable cancer cells present after completion of therapy. These cells can be detectable with many different methods but most commonly by flow cytometry or polymerase chain reaction (PCR). Risk-adapted approaches incorporating MRD assessments have been firmly established in other hematologic malignancies, most notably chronic myelogenous leukemia (CML) and ALL, and is currently under investigation in MCL.

A recent study in the contemporary era showed that young patients (age $\leq 65$ ) who received auto-HCT in CR1 had superior PFS than those who did not (75 versus 44 months, respectively) [119]. In this study, $76 \%$ of patients achieved a CR before proceeding to transplant. This group of patients still maintained a significant PFS benefit on subset analysis. A study looked at the prognostic significance of MRD status in patients who are in $\mathrm{CR}$ after induction while treated on two prospective European MCL clinical trials. In the study, the absence of MRD (as assessed by either flow cytometry or allelespecific oligonucleotide PCR (ASO-PCR) for IgH or cyclinD1 rearrangement) was shown to be associated with a more prolonged response duration compared to patients with MRD positivity in patients who achieved a CR after induction therapy (2-year response duration; 94\% versus 71\%) [120]. However, the potential benefit of transplant in MRD-negative patients could not be determined as all eligible young patients in this study went on to receive transplants.

Given the toxicities and resource utilization of autoHCTs, patients in CR after induction chemotherapy with MRD negativity are an ideal group for a prospective risk-adapted study. The ECOG-ACRIN 4151 study is a phase III randomized study that is currently ongoing in which patients (ages 18-70) that achieve MRD negativity after undergoing induction chemotherapy (with regimen at the discretion of treating physician) will be randomized to either rituximab maintenance therapy or autoHCT followed by maintenance rituximab. MRD assessment is from peripheral blood assessing for circulating tumor DNA (ctDNA) with immunoglobulin high throughput sequencing (Ig-HTS). The study is powered for OS at 6 years following induction therapy.

Another potential risk-adapted approach that has gained considerable attention recently is the measurement of ctDNA levels at regular intervals throughout the course of therapy rather than once after therapy. This approach may provide more sensitive and frequent therapy response assessment compared to interim PET or CT imaging and thus provide more opportunities for a change of therapy if the anticipated response is not achieved. This approach is analogous to response monitoring of CML to TKI therapy by PCR assessment of the peripheral blood for Bcr-Abl transcripts that is now standard of care. Two studies in MCL shown that achieving decreased ctDNA levels earlier during chemotherapy was associated with a better PFS [121, 122]. 
Many MCL trials using targeted therapies are incorporating MRD assessments into their protocols as secondary endpoints. This data will be valuable in creating future prospective studies exploring whether shorter courses of therapy could be given in patients who achieve MRD negativity without compromising long-term outcomes. In addition to response assessment, ctDNA testing can theoretically detect the presence of new mutations that predict therapy resistance potentially allowing a change of therapy sooner than when the progressive disease is detected. More prospective MRD based risk-adapted trials will likely be on the horizon, which will hopefully bring MRD analysis into regular clinical practice in MCL.

\section{Conclusions}

How will we approach MCL treatment in the future?

One of the hot topics in the field of MCL is whether chemo-free approaches using targeted agents will fully supplant chemotherapy in the upfront setting. Although ibrutinib and rituximab have shown good clinical activity in treatment naïve MCL patients and chemo-free combinatorial approaches (ibrutinib, venetoclax, and antiCD20 therapy) have gained ground in the frontline treatment of CLL, it is still early days in the world of MCL to abandon chemotherapy in the frontline setting at this time. On the other hand, a combination of novel agents and chemotherapy appears promising. The SHINE and TRIANGLE studies will be able to provide a more definitive answer.

For the younger patient, a chemo-free approach may be an option for the low-risk patient (MIPI low/intermediate) although its role in more aggressive disease with high Ki-67 is less clear. Incorporating targeted agents to reduce the amount of chemotherapy needed to obtain the same durable response, such as in NCT02427620, maybe a more attractive approach. Incorporating MRD negativity prospectively to decide if further consolidative chemotherapy is necessary, as in ECOG 4151, would be valuable if targeted agents are used upfront.

For relapsed/refractory MCL, with the recent results of ZUMA-2, CART therapy will likely play a crucial role in this setting, most notably for patients who progress on BTK inhibitors where there are no therapies currently available to achieve a durable response. BiTe antibodies have shown promising results in heavily pre-treated relapsed/refractory MCL, including those who had previously received CART, which provides yet another option in the growing armamentarium of MCL therapeutics. However, their place in the MCL treatment paradigm will need to be better defined, particularly whether they should be used earlier on, perhaps after BTK inhibitor failure, or following the progression on CART.
With the large number of ongoing studies in MCL, it is no doubt a very exciting time in the field. Given the rarity of MCL compared to other B cell malignancies, it will take time for clinical trials to fully mature to change standards of care. Hence, it is extremely important to enroll patients on clinical trials. With time, the way we treat MCL is going to change significantly in the not so distant future with new approaches shaping multiple levels of treatment.

\begin{abstract}
Abbreviations
Allo-HCT: Allogeneic hematopoietic stem cell transplantation; AutoHCT: Autologous hematopoietic stem cell transplantation; BiTe: Bispecific T cell engager; BR: Bendamustine and rituximab; BTK: Bruton's tyrosine kinase; CAR: Chimeric antigen receptor; CR: Complete response; MCL: Mantle cell lymphoma; MIPI: Mantle cell lymphoma international prognostic index; NHL: Non-Hodgkin's lymphoma; ORR: Overall response rate; OS: Overall survival; PFS: Progression-free survival; R2: Lenalidomide (Revlimid) and rituximab; R-CHOP: Rituximab, cyclophosphamide, doxorubicin, vincristine, and prednisone
\end{abstract}

\section{Acknowledgements}

None

\section{Authors' contributions}

$\mathrm{WH}$ and NE were involved in the conception, design, and manuscript preparation. Both authors approved the final version of the manuscript.

\section{Funding}

None

\section{Availability of data and materials}

Not applicable

Ethics approval and consent to participate

Not applicable

\section{Consent for publication}

Not applicable

\section{Competing interests}

WH has no relevant COI. NE has received honoraria from the Pharmacyclics.

Received: 11 May 2020 Accepted: 9 June 2020

Published online: 17 June 2020

\section{References}

1. Swerdlow SH, Campo E, Pileri SA, Harris NL, Stein H, Siebert R, et al. The 2016 revision of the World Health Organization classification of lymphoid neoplasms. Blood. 2016;127(20):2375-90.

2. Epperla N, Hamadani M, Fenske TS, Costa LJ. Incidence and survival trends in mantle cell lymphoma. Br J Haematol. 2018;181(5):703-6.

3. Hoster E, Dreyling M, Klapper W, Gisselbrecht C, van Hoof A, Kluin-Nelemans $\mathrm{HC}$, et al. A new prognostic index (MIPI) for patients with advanced-stage mantle cell lymphoma. Blood. 2008;111(2):558-65.

4. Eskelund CW, Dahl C, Hansen JW, Westman M, Kolstad A, Pedersen LB, et al. TP53 mutations identify younger mantle cell lymphoma patients who do not benefit from intensive chemoimmunotherapy. Blood. 2017;130(17): 1903-10.

5. Pal Singh S, Dammeijer F, Hendriks RW. Role of Bruton's tyrosine kinase in B cells and malignancies. Mol Cancer. 2018;17(1):57.

6. Ma J, Lu P, Guo A, Cheng S, Zong H, Martin P, et al. Characterization of ibrutinib-sensitive and -resistant mantle lymphoma cells. Br J Haematol. 2014;166(6):849-61.

7. Long M, Beckwith K, Do P, Mundy BL, Gordon A, Lehman AM, et al. Ibrutinib treatment improves $T$ cell number and function in $\mathrm{CLL}$ patients. J Clin Invest. 2017;127(8):3052-64. 
8. Wang ML, Blum KA, Martin P, Goy A, Auer R, Kahl BS, et al. Long-term follow-up of MCL patients treated with single-agent ibrutinib: updated safety and efficacy results. Blood. 2015;126(6):739-45.

9. Wang M, Rule S, Martin P, Goy A, Auer R, Kahl BS, et al. Single-agent ibrutinib demonstrates safety and durability of response at 2 years follow-up in patients with relapsed or refractory mantle cell lymphoma: updated results of an international, multicenter, open-label phase 2 study. Blood. 2014;124(21):4453.

10. Dreyling M, Jurczak W, Jerkeman M, Silva RS, Rusconi C, Trneny M, et al. Ibrutinib versus temsirolimus in patients with relapsed or refractory mantlecell lymphoma: an international, randomised, open-label, phase 3 study. Lancet. 2016;387(10020):770-8.

11. Wang M, Rule S, Zinzani PL, Goy A, Casasnovas O, Smith SD, et al. Acalabrutinib in relapsed or refractory mantle cell lymphoma (ACE-LY-004): a single-arm, multicentre, phase 2 trial. Lancet. 2018;391(10121):659-67.

12. Wang M, Rule S, Zinzani PL, Goy A, Casasnovas O, Smith SD, et al. Durable response with single-agent acalabrutinib in patients with relapsed or refractory mantle cell lymphoma. Leukemia. 2019;33(11):2762-6.

13. Wang M, Rule S, Zinzani PL, Goy A, Casasnovas O, Smith SD, et al. Longterm follow-up of acalabrutinib monotherapy in patients with relapsed/ refractory mantle cell lymphoma. Blood. 2018;132(Supplement 1):2876.

14. Tam CS, Wang M, Simpson D, Opat S, Cull G, Munoz J, et al. Updated safety and activity of the investigational Bruton tyrosine kinase inhibitor zanubrutinib (BGB-3111) in patients with mantle cell lymphoma. Blood. 2018;132(Supplement 1):1592.

15. Song Y, Zhou K, Zou D, Zhou J, Hu J, Yang H, et al. Safety and Activity of the Investigational Bruton Tyrosine Kinase Inhibitor Zanubrutinib (BGB-3111) in patients with mantle cell lymphoma from a phase 2 trial. Blood. 2018; 132(Supplement 1):148.

16. Mato AR, Flinn IW, Pagel JM, Brown JR, Cheah CY, Coombs CC, et al. Results from a first-in-human, proof-of-concept phase 1 trial in pretreated B-cell malignancies for Loxo-305, a next-generation, highly selective, non-covalent BTK inhibitor. Blood. 2019;134(Supplement_1):501.

17. Woyach J, Stephens DM, Flinn IW, Bhat SA, Savage RE, Chai F, et al. Final results of phase 1, dose escalation study evaluating ARQ 531 in patients with relapsed or refractory B-cell lymphoid malignancies. Blood. 2019; 134(Supplement_1):4298.

18. Rule S, Dreyling M, Goy A, Hess G, Auer R, Kahl B, et al. Outcomes in 370 patients with mantle cell lymphoma treated with ibrutinib: a pooled analysis from three open-label studies. Br J Haematol. 2017;179(3):430-8.

19. Wu J, Zhang M, Liu D. Acalabrutinib (ACP-196): a selective secondgeneration BTK inhibitor. J Hematol Oncol. 2016;9:21.

20. Guo Y, Liu Y, Hu N, Yu D, Zhou C, Shi G, et al. Discovery of Zanubrutinib (BGB-3111), a Novel, potent, and selective covalent inhibitor of Bruton's tyrosine kinase. J Med Chem. 2019;62(17):7923-40.

21. Tam CS, Robak T, Ghia P, Kahl BS, Walker P, Janowski W, et al. Efficacy and safety of zanubrutinib in patients with treatment-naive chronic lymphocytic leukemia (CLL) or small lymphocytic lymphoma (SLL) with Del(17p): initial results from arm C of the sequoia (BGB-3111-304) trial. Blood. 2019; 134(Supplement_1):499.

22. Tam COS, Zhu J, Cull G, Gottlieb D, Li J, Marlton P, Qiu L, Roberts A, Seymour J, Simpson D, Song Y, Yang H, Du C, Feng S, Ji M, Lin L, Novotny W, Wang A, Trotman J. Pooled analysis of safety data from monotherapy studies of the bruton tyrosine kinase (BTK) inhibitor, zanubrutinib (BGB3111), in B-cell malignancies. Eur Hematol Assoc. 2018.

23. Martin P, Maddocks K, Leonard JP, Ruan J, Goy A, Wagner-Johnston N, et al. Postibrutinib outcomes in patients with mantle cell lymphoma. Blood. 2016 127(12):1559-63.

24. Epperla N, Hamadani M, Cashen AF, Ahn KW, Oak E, Kanate AS, et al. Predictive factors and outcomes for ibrutinib therapy in relapsed/refractory mantle cell lymphoma-a "real world" study. Hematol Oncol. 2017;35(4):528-35.

25. Jain P, Kanagal-Shamanna R, Zhang S, Ahmed M, Ghorab A, Zhang L, et al. Longterm outcomes and mutation profiling of patients with mantle cell lymphoma (MCL) who discontinued ibrutinib. Br J Haematol. 2018;183(4):578-87.

26. Gomez EB, Isabel L, Rosendahal MS, Rothenberg SM, Andrews SW, Brandhuber BJ. Loxo-305, a highly selective and non-covalent next generation BTK inhibitor, inhibits diverse BTK C481 substitution mutations. Blood. 2019:134(Supplement 1):4644.

27. Reiff SD, Mantel R, Smith LL, Greene JT, Muhowski EM, Fabian CA, et al. The BTK inhibitor ARQ 531 targets ibrutinib-resistant CLL and richter transformation. Cancer Discov. 2018;8(10):1300-15.
28. Deng C, Lee $\mathrm{S}, \mathrm{O}^{\prime}$ Connor OA. New strategies in the treatment of mantle cell lymphoma. Clin Cancer Res. 2012;18(13):3499-508.

29. Soncini D, Orecchioni S, Ruberti S, Minetto P, Martinuzzi C, Agnelli L, et al. The new small molecule tyrosine-kinase inhibitor ARQ531 targets acute myeloid leukemia cells by disrupting multiple tumor-addicted programs. Haematologica. 2019.

30. Davids MS, Roberts AW, Seymour JF, Pagel JM, Kahl BS, Wierda WG, et al. Phase I first-in-human study of venetoclax in patients with relapsed or refractory non-Hodgkin lymphoma. J Clin Oncol. 2017;35(8):826-33.

31. Khoury JD, Medeiros $\sqcup$, Rassidakis GZ, McDonnell TJ, Abruzzo LV, Lai R. Expression of $\mathrm{Mcl}-1$ in mantle cell lymphoma is associated with high-grade morphology, a high proliferative state, and p53 overexpression. J Pathol. 2003;199(1):90-7.

32. Dengler MA, Teh CE, Thijssen R, Gangoda L, Lan P, Herold MJ, et al. Potent efficacy of MCL-1 inhibitor-based therapies in preclinical models of mantle cell lymphoma. Oncogene. 2020;39(9):2009-23.

33. Prukova D, Andera L, Nahacka Z, Karolova J, Svaton M, Klanova M, et al. Cotargeting of BCL2 with venetoclax and MCL1 with S63845 is synthetically lethal in vivo in relapsed mantle cell lymphoma. Clin Cancer Res. 2019; 25(14):4455-65.

34. Pham LV, Tamayo AT, Yoshimura LC, Lo P, Ford RJ. Inhibition of constitutive NF-kappa B activation in mantle cell lymphoma B cells leads to induction of cell cycle arrest and apoptosis. J Immunol. 2003;171(1):88-95.

35. Perez-Galan P, Roue G, Villamor N, Montserrat E, Campo E, Colomer D. The proteasome inhibitor bortezomib induces apoptosis in mantle-cell lymphoma through generation of ROS and Noxa activation independent of p53 status. Blood. 2006;107(1):257-64.

36. Fisher RI, Bernstein SH, Kahl BS, Djulbegovic B, Robertson MJ, de Vos S, et al. Multicenter phase II study of bortezomib in patients with relapsed or refractory mantle cell lymphoma. J Clin Oncol. 2006;24(30):4867-74.

37. Goy A, Bernstein SH, Kahl BS, Djulbegovic B, Robertson MJ, de Vos S, et al. Bortezomib in patients with relapsed or refractory mantle cell lymphoma: updated time-to-event analyses of the multicenter phase 2 PINNACLE study. Ann Oncol. 2009;20(3):520-5.

38. Zhang L, Pham LV, Newberry KJ, Ou Z, Liang R, Qian J, et al. In vitro and in vivo therapeutic efficacy of carfilzomib in mantle cell lymphoma: targeting the immunoproteasome. Mol Cancer Ther. 2013;12(11):2494-504.

39. Shah C, Bishnoi R, Jain A, Bejjanki H, Xiong S, Wang Y, et al. Cardiotoxicity associated with carfilzomib: systematic review and meta-analysis. Leuk Lymphoma. 2018;59(11):2557-69.

40. Lee HJ, Badillo M, Romaguera J, Wang M. A phase II study of carfilzomib in the treatment of relapsed/refractory mantle cell lymphoma. Br J Haematol. 2019;184(3):460-2.

41. Song K, Herzog BH, Sheng M, Fu J, McDaniel JM, Chen H, et al. Lenalidomide inhibits lymphangiogenesis in preclinical models of mantle cell lymphoma. Cancer Res. 2013;73(24):7254-64.

42. Reddy N, Hernandez-Ilizaliturri FJ, Deeb G, Roth M, Vaughn M, Knight J, et al. Immunomodulatory drugs stimulate natural killer-cell function, alter cytokine production by dendritic cells, and inhibit angiogenesis enhancing the anti-tumour activity of rituximab in vivo. $\mathrm{Br} J$ Haematol. 2008;140(1):36-45.

43. Zhang L, Qian Z, Cai Z, Sun L, Wang H, Bartlett JB, et al. Synergistic antitumor effects of lenalidomide and rituximab on mantle cell lymphoma in vitro and in vivo. Am J Hematol. 2009;84(9):553-9.

44. Petrakis G, Veloza L, Clot G, Gine E, Gonzalez-Farre B, Navarro A, et al. Increased tumour angiogenesis in SOX11-positive mantle cell lymphoma. Histopathology. 2019;75(5):704-14.

45. Habermann TM, Lossos IS, Justice G, Vose JM, Wiernik PH, McBride K, et al. Lenalidomide oral monotherapy produces a high response rate in patients with relapsed or refractory mantle cell lymphoma. Br J Haematol. 2009; 145(3):344-9.

46. Zinzani PL, Vose JM, Czuczman MS, Reeder CB, Haioun C, Polikoff J, et al. Long-term follow-up of lenalidomide in relapsed/refractory mantle cell lymphoma: subset analysis of the NHL-003 study. Ann Oncol. 2013;24(11): 2892-7.

47. Vose JM, Habermann TM, Czuczman MS, Zinzani PL, Reeder CB, Tuscano JM, et al. Single-agent lenalidomide is active in patients with relapsed or refractory aggressive non-Hodgkin lymphoma who received prior stem cell transplantation. Br J Haematol. 2013;162(5):639-47.

48. Goy A, Sinha R, Williams ME, Kalayoglu Besisik S, Drach J, Ramchandren R, et al. Single-agent lenalidomide in patients with mantle-cell lymphoma who 
relapsed or progressed after or were refractory to bortezomib: phase I MCL-001 (EMERGE) study. J Clin Oncol. 2013;31(29):3688-95.

49. Trneny M, Lamy T, Walewski J, Belada D, Mayer J, Radford J, et al. Lenalidomide versus investigator's choice in relapsed or refractory mantle cell lymphoma (MCL-002; SPRINT): a phase 2, randomised, multicentre trial. Lancet Oncol. 2016;17(3):319-31.

50. Desai M, Newberry K, Ou Z, Wang M, Zhang L. Lenalidomide in relapsed or refractory mantle cell lymphoma: overview and perspective. Ther Adv Hematol. 2014;5(3):91-101.

51. Heinrich DA, Weinkauf M, Hutter $G$, Zimmermann $Y$, Jurinovic $V$, Hiddemann $W$, et al. Differential regulation patterns of the anti-CD20 antibodies obinutuzumab and rituximab in mantle cell lymphoma. $\mathrm{Br} J$ Haematol. 2015;168(4):606-10.

52. Morschhauser FA, Cartron G, Thieblemont C, Solal-Celigny P, Haioun C, Bouabdallah R, et al. Obinutuzumab (GA101) monotherapy in relapsed/ refractory diffuse large b-cell lymphoma or mantle-cell lymphoma: results from the phase II GAUGUIN study. J Clin Oncol. 2013;31(23):2912-9.

53. Klein U, Tu Y, Stolovitzky GA, Mattioli M, Cattoretti G, Husson H, et al. Gene expression profiling of $B$ cell chronic lymphocytic leukemia reveals a homogeneous phenotype related to memory B cells. J Exp Med. 2001; 194(11):1625-38

54. Rosenwald A, Alizadeh AA, Widhopf G, Simon R, Davis RE, Yu X, et al. Relation of gene expression phenotype to immunoglobulin mutation genotype in $B$ cell chronic lymphocytic leukemia. J Exp Med. 2001;194(11):1639-47.

55. Barna G, Mihalik R, Timar B, Tombol J, Csende Z, Sebestyen A, et al. ROR1 expression is not a unique marker of CLL. Hematol Oncol. 2011;29(1):17-21.

56. Yu J, Chen L, Cui B, Widhopf GF 2nd, Shen Z, Wu R, et al. Wnt5a induces ROR1/ROR2 heterooligomerization to enhance leukemia chemotaxis and proliferation. J Clin Invest. 2016;126(2):585-98.

57. Yu J, Chen Y, Chen L, Zhang L, Rassenti LZ, Widhopf GF 2nd, et al. Cirmtuzumab inhibits ibrutinib-resistant, Wnt5a-induced Rac1 activation and proliferation in mantle cell lymphoma. Oncotarget. 2018;9(37):24731-6.

58. Choi MY, Widhopf GF 2nd, Ghia EM, Kidwell RL, Hasan MK, Yu J, et al. Phase I trial: cirmtuzumab inhibits ROR1 signaling and stemness signatures in patients with chronic lymphocytic leukemia. Cell Stem Cell. 2018;22(6):951-9 e3.

59. Pagel JM, Spurgeon SE, Byrd JC, Awan FT, Flinn IW, Lanasa MC, et al. Otlertuzumab (TRU-016), an anti-CD37 monospecific ADAPTIR0 therapeutic protein, for relapsed or refractory NHL patients. Br J Haematol. 2015;168(1):38-45.

60. Alinari L, Mahoney E, Patton J, Zhang X, Huynh L, Earl CT, et al. FTY720 increases CD74 expression and sensitizes mantle cell lymphoma cells to milatuzumab-mediated cell death. Blood. 2011;118(26):6893-903.

61. Martin P, Furman RR, Rutherford S, Ruan J, Ely S, Greenberg J, et al. Phase I study of the anti-CD74 monoclonal antibody milatuzumab (hLL1) in patients with previously treated B-cell lymphomas. Leuk Lymphoma. 2015; 56(11):3065-70.

62. Okazaki M, Luo Y, Han T, Yoshida M, Seon BK. Three new monoclonal antibodies that define a unique antigen associated with prolymphocytic leukemia/non-Hodgkin's lymphoma and are effectively internalized after binding to the cell surface antigen. Blood. 1993;81(1):84-94.

63. Sehn LH, Herrera AF, Flowers CR, Kamdar MK, McMillan A, Hertzberg M, et al. Polatuzumab vedotin in relapsed or refractory diffuse large B-cell lymphoma. J Clin Oncol. 2020;38(2):155-65.

64. Thota S, Advani A. Inotuzumab ozogamicin in relapsed B-cell acute lymphoblastic leukemia. Eur J Haematol. 2017;98(5):425-34.

65. Dang $\mathrm{NH}$, Ogura M, Castaigne $\mathrm{S}$, Fayad LE, Jerkeman M, Radford J, et al. Randomized, phase 3 trial of inotuzumab ozogamicin plus rituximab versus chemotherapy plus rituximab for relapsed/refractory aggressive B-cell nonHodgkin lymphoma. Br J Haematol. 2018;182(4):583-6.

66. Morschhauser F, Flinn IW, Advani R, Sehn LH, Diefenbach C, Kolibaba K, et al. Polatuzumab vedotin or pinatuzumab vedotin plus rituximab in patients with relapsed or refractory non-Hodgkin lymphoma: final results from a phase 2 randomised study (ROMULUS). Lancet Haematol. 2019;6(5): e254-e65.

67. Maclaren AP, Levin N, Lowman H. Abstract 835: TRPH-222, a novel antiCD22 antibody drug conjugate (ADC), has significant anti-tumor activity in NHL xenografts and reduces B cells in monkeys. Cancer Res. 2018;78(13 Supplement):835.

68. Kahl BS, Hamadani M, Radford J, Carlo-Stella C, Caimi P, Reid E, et al. A phase study of ADCT-402 (Loncastuximab Tesirine), a novel pyrrolobenzodiazepinebased antibody-drug conjugate, in relapsed/refractory B-cell non-Hodgkin lymphoma. Clin Cancer Res. 2019;25(23):6986-94.
69. Trneny M, Verhoef G, Dyer MJ, Ben Yehuda D, Patti C, Canales M, et al. A phase II multicenter study of the anti-CD19 antibody drug conjugate coltuximab ravtansine (SAR3419) in patients with relapsed or refractory diffuse large B-cell lymphoma previously treated with rituximab-based immunotherapy. Haematologica. 2018;103(8):1351-8.

70. Coiffier B, Thieblemont C, de Guibert S, Dupuis J, Ribrag V, Bouabdallah R, et al. A phase II, single-arm, multicentre study of coltuximab ravtansine (SAR3419) and rituximab in patients with relapsed or refractory diffuse large B-cell lymphoma. Br J Haematol. 2016;173(5):722-30.

71. Moskowitz $\mathrm{CH}$, Fanale MA, Shah BD, Advani $\mathrm{RH}$, Chen R, Kim S, et al. A phase 1 study of denintuzumab mafodotin (SGN-CD19A) in relapsed/ refactory B-lineage non-Hodgkin lymphoma. Blood. 2015;126(23):182.

72. Deckert J, Park PU, Chicklas S, Yi Y, Li M, Lai KC, et al. A novel anti-CD37 antibody-drug conjugate with multiple anti-tumor mechanisms for the treatment of B-cell malignancies. Blood. 2013;122(20):3500-10.

73. Stathis A, Flinn IW, Madan S, Maddocks K, Freedman A, Weitman S, et al. Safety, tolerability, and preliminary activity of IMGN529, a CD37-targeted antibody-drug conjugate, in patients with relapsed or refractory B-cell nonHodgkin lymphoma: a dose-escalation, phase I study. Investig New Drugs. 2018;36(5):869-76

74. Sawas A, Savage KJ, Perez R, Advani RH, Butturini A, Lackey J, et al. A phase 1 study of the anti-CD37 antibody-drug conjugate AGS67E in advanced lymphoid malignancies. Interim Results. Blood. 2015;126(23):3976.

75. Wang ML, Lee $H$, Chuang $H$, Wagner-Bartak N, Hagemeister F, Westin J, et al. Ibrutinib in combination with rituximab in relapsed or refractory mantle cell lymphoma: a single-centre, open-label, phase 2 trial. Lancet Oncol. 2016;17(1):48-56.

76. Tam CS, Anderson MA, Pott C, Agarwal R, Handunnetti S, Hicks RJ, et al. Ibrutinib plus venetoclax for the treatment of mantle-cell lymphoma. N Engl Med. 2018:378(13):1211-23.

77. Handunnetti SM, Anderson MA, Burbury K, Hicks RJ, Birbirsa B, Bressel M, et al. Three year update of the phase II ABT-199 (venetoclax) and Ibrutinib in mantle cell lymphoma (AIM) study. Blood. 2019;134(Supplement_1):756.

78. Le Gouill S, Morschhauser F, Bouabdallah K, Cartron G, Casasnovas R-O, Milpied N-J, et al. Ibrutinib plus obinutuzumab and venetoclax in relapsed/ refractory mantle cells lymphoma patients, results of the OASIS phase i clinical trial. Blood. 2018;132(Supplement 1):4158.

79. Wang M, Fayad L, Wagner-Bartak N, Zhang L, Hagemeister F, Neelapu SS, et al. Lenalidomide in combination with rituximab for patients with relapsed or refractory mantle-cell lymphoma: a phase 1/2 clinical trial. Lancet Oncol. 2012;13(7):716-23.

80. Chong EA, Ahmadi T, Aqui NA, Svoboda J, Nasta SD, Mato AR, et al. Combination of lenalidomide and rituximab overcomes rituximab resistance in patients with indolent B-cell and mantle cell lymphomas. Clin Cancer Res. 2015;21(8):1835-42.

81. Jerkeman M, Eskelund CW, Hutchings M, Raty R, Wader KF, Laurell A, et al. Ibrutinib, lenalidomide, and rituximab in relapsed or refractory mantle cell lymphoma (PHILEMON): a multicentre, open-label, single-arm, phase 2 trial. Lancet Haematol. 2018;5(3):e109-e16.

82. Martin P, Bartlett NL, Blum KA, Park S, Maddocks K, Ruan J, et al. A phase 1 trial of ibrutinib plus palbociclib in previously treated mantle cell lymphoma. Blood. 2019;133(11):1201-4.

83. Zhao X, Bodo J, Sun D, Durkin L, Lin J, Smith MR, et al. Combination of ibrutinib with ABT-199: synergistic effects on proliferation inhibition and apoptosis in mantle cell lymphoma cells through perturbation of BTK, AKT and BCL2 pathways. Br J Haematol. 2015;168(5):765-8.

84. Chiron D, Bellanger C, Papin A, Tessoulin B, Dousset C, Maiga S, et al. Rational targeted therapies to overcome microenvironment-dependent expansion of mantle cell lymphoma. Blood. 2016;128(24):2808-18.

85. Le Gouill S, Morschhauser F, Bouabdallah K, Cartron G, Casasnovas O, Gastinne T, et al. Ibrutinib, venetoclax plus obinutuzumab in newly diagnosed mantle cell lymphoma patients. Blood. 2019;134(Supplement_1):1530.

86. McCulloch R, Visco C, Eyre TA, Frewin R, Phillips N, Tucker DL, et al. Efficacy of R-BAC in relapsed, refractory mantle cell lymphoma post BTK inhibitor therapy. Br J Haematol. 2020.

87. Lee C, Huang X, Di Liberto M, Martin P, Chen-Kiang S. Targeting CDK4/6 in mantle cell lymphoma. Ann Lymphoma. 2020;4

88. Leonard JP, LaCasce AS, Smith MR, Noy A, Chirieac LR, Rodig SJ, et al. Selective CDK4/6 inhibition with tumor responses by PD0332991 in patients with mantle cell lymphoma. Blood. 2012;119(20):4597-607.

89. Chiron D, Martin P, Di Liberto M, Huang X, Ely S, Lannutti BJ, et al. Induction of prolonged early $\mathrm{G} 1$ arrest by CDK4/CDK6 inhibition reprograms 
lymphoma cells for durable PI3Kdelta inhibition through PIK3IP1. Cell Cycle. 2013;12(12):1892-900.

90. Dey J, Deckwerth TL, Kerwin WS, Casalini JR, Merrell AJ, Grenley MO, et al. Voruciclib, a clinical stage oral CDK9 inhibitor, represses MCL-1 and sensitizes high-risk diffuse large B-cell lymphoma to BCL2 inhibition. Sci Rep. 2017;7(1):18007.

91. Wang M, Munoz J, Goy A, Locke FL, Jacobson CA, Hill BT, et al. KTE-X19 CAR T-cell therapy in relapsed or refractory mantle-cell lymphoma. N Engl J Med. 2020;382(14):1331-42.

92. Neelapu SS, Locke FL, Bartlett NL, Lekakis LJ, Miklos DB, Jacobson CA, et al. Axicabtagene ciloleucel CAR T-cell therapy in refractory large B-cell lymphoma. N Engl J Med. 2017;377(26):2531-44.

93. Schuster SJ, Bishop MR, Tam CS, Waller EK, Borchmann P, McGuirk JP, et al. Tisagenlecleucel in adult relapsed or refractory diffuse large B-cell lymphoma. N Engl J Med. 2019;380(1):45-56.

94. Goebeler ME, Bargou R. Blinatumomab: a CD19/CD3 bispecific T cell engager (BiTE) with unique anti-tumor efficacy. Leuk Lymphoma. 2016;57(5):1021-32.

95. Goebeler ME, Knop S, Viardot A, Kufer P, Topp MS, Einsele H, et al. Bispecific T-cell engager (BiTE) antibody construct blinatumomab for the treatment of patients with relapsed/refractory non-Hodgkin lymphoma: final results from a phase i study. J Clin Oncol. 2016;34(10):1104-11.

96. Dufner V, Sayehli CM, Chatterjee M, Hummel HD, Gelbrich G, Bargou RC, et al. Long-term outcome of patients with relapsed/refractory B-cell non-Hodgkin lymphoma treated with blinatumomab. Blood Adv. 2019;3(16):2491-8.

97. Schuster SJ, Bartlett NL, Assouline S, Yoon S-S, Bosch F, Sehn LH, et al. Mosunetuzumab induces complete remissions in poor prognosis non-Hodgkin lymphoma patients, including those who are resistant to or relapsing after chimeric antigen receptor T-cell (CAR-T) therapies, and is active in treatment through multiple lines. Blood. 2019;134(Supplement_1):6.

98. Bannerji R, Allan JN, Arnason JE, Brown JR, Advani RH, Barnes JA, et al. Clinical activity of REGN1979, a bispecific human, anti-CD20 $\mathrm{x}$ anti-CD3 antibody, in patients with relapsed/refractory (R/R) B-cell non-Hodgkin lymphoma (B-NHL). Blood. 2019;134(Supplement_1):762.

99. Lugtenburg P, Mous R, Clausen MR, Chamuleau MED, Johnson P, Linton K, et al. First-in-human, phase $1 / 2$ trial to assess the safety and clinical activity of subcutaneous GEN3013 (DuoBody ${ }^{\oplus}$-CD3 × CD20) in B-cell non-Hodgkin lymphomas. Blood. 2019;134(Supplement_1):758.

100. Engelberts PJ, Hiemstra IH, de Jong B, Schuurhuis DH, Meesters J, Beltran Hernandez I, et al. DuoBody-CD3xCD20 induces potent T-cell-mediated killing of malignant B cells in preclinical models and provides opportunities for subcutaneous dosing. EBioMedicine. 2020;52:102625.

101. Romaguera JE, Wang M, Feng L, Fayad LE, Hagemeister F, McLaughlin P, et al. Phase 2 trial of bortezomib in combination with rituximab plus hyperfractionated cyclophosphamide, vincristine, doxorubicin, and dexamethasone alternating with bortezomib, rituximab, methotrexate, and cytarabine for untreated mantle cell lymphoma. Cancer. 2018;124(12):2561-9.

102. William BM, Allen MS, Loberiza FR Jr, Bociek RG, Bierman PJ, Armitage JO, et al. Phase I/II study of bortezomib-BEAM and autologous hematopoietic stem cell transplantation for relapsed indolent non-Hodgkin lymphoma, transformed, or mantle cell lymphoma. Biol Blood Marrow Transplant. 2014; 20(4):536-42.

103. Kaplan LD, Maurer MJ, Stock W, Bartlett NL, Fulton N, Pettinger A, et al. Bortezomib maintenance (BM) or consolidation (BC) following aggressive immunochemotherapy and autologous stem cell transplant (ASCT) for untreated mantle cell lymphoma (MCL): 8 year follow up of CALGB 50403 (Alliance). Blood. 2018;132(Supplement 1):146.

104. Doorduijn JK, Minnema MC, Kersten MJ, Lugtenburg PJ, Schipperus MR, van Marwijk Kooy M, et al. Bortezomib maintenance therapy after induction with R-CHOP, ARA-C and autologous stem cell transplantation in newly diagnosed MCL patients, results of a multicenter phase II HOVON study. Blood. 2015;126(23):339.

105. Doorduijn JK, Zijlstra JM, Lugtenburg PJ, Kersten MJ, Bohmer LH, Minnema MC, et al. Bortezomib maintenance after R-CHOP, cytarabine and autologous stem cell transplantation in newly diagnosed patients with mantle cell lymphoma, results of a randomised phase II HOVON trial. Br J Haematol. 2020

106. Ruan J, Martin P, Christos P, Cerchietti L, Tam W, Shah B, et al. Five-year follow-up of lenalidomide plus rituximab as initial treatment of mantle cell lymphoma. Blood. 2018;132(19):2016-25.

107. Ruan J, Leonard JP. Lenalidomide plus rituximab for mantle-cell lymphoma. N Engl J Med. 2016;374(8):793.
108. Dreyling M, Ladetto M, Doorduijn JK, Gine E, Jerkeman M, Mey U, et al. Triangle: autologous transplantation after a rituximab/ibrutinib/ara-c containing induction in generalized mantle cell lymphoma - a randomized European MCL Network Trial. Blood. 2019;134(Supplement_1):2816.

109. Wang $M$, Jain $P$, Zhang $S$, Nomie $K$, Wang $L$, Oriabure $O$, et al. Ibrutinib with rituximab (IR) and short course R-HYPERCVAD/MTX is very efficacious in previously untreated young PTS with mantle cell lymphoma (MCL). Hematol Oncol. 2019;37(S2):42-3.

110. Kaplan LD, Jung S-H, Stock W, Bartlett NL, Pitcher B, Byrd JC, et al. Bortezomib maintenance (BM) Versus Consolidation (BC) Following Aggressive Immunochemotherapy and autologous stem cell transplant (ASCT) for untreated mantle cell lymphoma (MCL): CALGB (Alliance) 50403. Blood. 2015;126(23):337.

111. Morschhauser F, Fowler NH, Feugier P, Bouabdallah R, Tilly H, Palomba ML, et al. Rituximab plus lenalidomide in advanced untreated follicular lymphoma. N Engl J Med. 2018;379(10):934-47.

112. Ruan J, Martin P, Shah B, Schuster SJ, Smith SM, Furman RR, et al. Lenalidomide plus rituximab as initial treatment for mantle-cell lymphoma. N Engl J Med. 2015;373(19):1835-44.

113. Albertsson-Lindblad A, Kolstad A, Laurell A, Raty R, Gronbaek K, Sundberg J, et al. Lenalidomide-bendamustine-rituximab in patients older than 65 years with untreated mantle cell lymphoma. Blood. 2016;128(14):1814-20.

114. Maddocks K, Christian B, Jaglowski S, Flynn J, Jones JA, Porcu P, et al. A phase $1 / 1 \mathrm{~b}$ study of rituximab, bendamustine, and ibrutinib in patients with untreated and relapsed/refractory non-Hodgkin lymphoma. Blood. 2015; 125(2):242-8.

115. de Vos S, Swinnen L, Wang D, Reid E, Fowler N, Cordero J, et al. Venetoclax, bendamustine, and rituximab in patients with relapsed or refractory NHL: a phase lb dose-finding study. Ann Oncol. 2018;29(9): $1932-8$.

116. Zinzani PL, Topp MS, Yuen SL, Rusconi C, Fleury I, Pro B, et al. Phase 2 study of venetoclax plus rituximab or randomized ven plus bendamustine+ rituximab (BR) versus BR in patients with relapsed/refractory follicular lymphoma: interim data. Blood. 2016;128(22):617.

117. Portell CA, Bennani NN, Jegede O, Naik S, Parsons BM, Patel PP, et al. Bendamustine and rituximab plus venetoclax in untreated mantle cell lymphoma over 60 years of age (PrE0405): a phase II study. Blood. 2019; 134(Supplement_1):5243.

118. Jain $\mathrm{P}$, Lee HJ, Steiner RE, Hagemeister FB, Samaniego F, Westin JR, et al. Frontline treatment with ibrutinib with rituximab (IR) combination is highly effective in elderly ( $\geq 65$ years) patients with mantle cell lymphoma (MCL) results from a phase ii trial. Blood. 2019;134(Supplement_1):3988.

119. Gerson JN, Handorf E, Villa D, Gerrie AS, Chapani P, Li S, et al. Survival outcomes of younger patients with mantle cell lymphoma treated in the rituximab era. J Clin Oncol. 2019;37(6):471-80.

120. Pott C, Hoster E, Delfau-Larue MH, Beldjord K, Bottcher S, Asnafi V, et al. Molecular remission is an independent predictor of clinical outcome in patients with mantle cell lymphoma after combined immunochemotherapy: a European MCL intergroup study. Blood. 2010; 115(16):3215-23.

121. Lakhotia R, Melani C, Pittaluga S, Dunleavy K, Saba NS, Lucas AN, et al. Circulating tumor DNA dynamics during therapy predict outcomes in mantle cell lymphoma. Blood. 2018;132(Supplement 1):147.

122. Ferrero S, Daniela B, Lo Schirico M, Evangelista A, Cifaratti A, Drandi D, et al. Comprehensive minimal residual disease (MRD) analysis of the Fondazione Italiana Linfomi (FIL) MCL0208 clinical trial for younger patients with mantle cell lymphoma: a kinetic model ensures a more refined risk stratification. Blood. 2018;132(Supplement 1):920.

\section{Publisher's Note}

Springer Nature remains neutral with regard to jurisdictional claims in published maps and institutional affiliations. 